NASA/TM-1999-107249, Chapter 9

Chemical-Vapor-Deposited Diamond Film

Kazuhisa Miyoshi

Lewis Research Center, Cleveland, Ohio 
Since its founding, NASA has been dedicated to the advancement of aeronautics and space science. The NASA Scientific and Technical Information (STI) Program Office plays a key part in helping NASA maintain this important role.

The NASA STI Program Office is operated by Langley Research Center, the Lead Center for NASA's scientific and technical information. The NASA STI Program Office provides access to the NASA STI Database, the largest collection of aeronautical and space science STI in the world. The Program Office is also NASA's institutional mechanism for disseminating the results of its research and development activities. These results are published by NASA in the NASA STI Report Series, which includes the following report types:

- TECHNICAL PUBLICATION. Reports of completed research or a major significant phase of research that present the results of NASA programs and include extensive data or theoretical analysis. Includes compilations of significant scientific and technical data and information deemed to be of continuing reference value. NASA's counterpart of peerreviewed formal professional papers but has less stringent limitations on manuscript length and extent of graphic presentations.

- TECHNICAL MEMORANDUM. Scientific and technical findings that are preliminary or of specialized interest, e.g., quick release reports, working papers, and bibliographies that contain minimal annotation. Does not contain extensive analysis.

- CONTRACTOR REPORT. Scientific and technical findings by NASA-sponsored contractors and grantees.
- CONFERENCE PUBLICATION. Collected papers from scientific and technical conferences, symposia, seminars, or other meetings sponsored or cosponsored by NASA.

- SPECIAL PUBLICATION. Scientific, technical, or historical information from NASA programs, projects, and missions, often concerned with subjects having substantial public interest.

- TECHNICAL TRANSLATION. Englishlanguage translations of foreign scientific and technical material pertinent to NASA's mission.

Specialized services that complement the STI Program Office's diverse offerings include creating custom thesauri, building customized data bases, organizing and publishing research results ... even providing videos.

For more information about the NASA STI Program Office, see the following:

- Access the NASA STI Program Home Page at http://www.sti.nasa.gov

- E-mail your question via the Internet to help@sti.nasa.gov

- Fax your question to the NASA Access Help Desk at (301) 621-0134

- Telephone the NASA Access Help Desk at (301) 621-0390

- Write to:

NASA Access Help Desk

NASA Center for AeroSpace Information 7121 Standard Drive

Hanover, MD 21076 
NASA/TM-1999-107249, Chapter 9

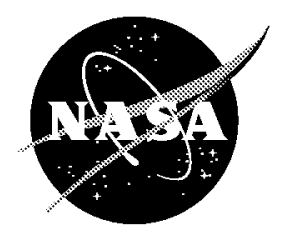

\section{Chemical-Vapor-Deposited Diamond Film}

Kazuhisa Miyoshi

Lewis Research Center, Cleveland, Ohio

National Aeronautics and

Space Administration

Lewis Research Center 
Available from

NASA Center for Aerospace Information 7121 Standard Drive

Hanover, MD 21076

Price Code: A03
National Technical Information Service 5287 Port Royal Road Springfield, VA 22100 Price Code: A03 


\section{Chapter 9}

\section{Chemical-Vapor-Deposited Diamond Film}

\subsection{Introduction}

Chemical-vapor-deposited (CVD) diamond film technology looks promising in the field of tribology [9.1-9.5]. CVD diamond coatings offer a broader tribological potential than do natural and high-pressure synthetic diamonds because size and eventually cost will be less of a limitation. In general, however, the advantages and utility of CVD diamond as an industrial ceramic can only be realized if the price is right [9.6]. Until recently skeptics, even internationally well-known tribologists, viewed this technology merely as a rich mother lode of research papers for the academic community. According to Windischmann [9.6] that view may no longer be valid because of two advantages made by a leading CVD diamond supplier in the past year:

1. Reduction of the cost of CVD diamond deposition below $\$ 5 / \mathrm{carat}\left(\$ 8 / \mathrm{cm}^{2}\right)$

2. Installation of production capacity

Thus, CVD diamond applications and business in the field of tribology, particularly cutting and forming tools, are an industrial reality [9.1]. At present CVD diamond is produced in the form of coatings or wafers. In this respect it is similar to pyrolytic graphite. Most CVD diamond is produced as films of polycrystalline diamond on ceramic or metal substrates. Coatings with a thickness of submicrometer to $1 \mathrm{~mm}$ or more are routinely produced. Thin CVD diamond films are used in film form; thick films are used in a free-standing shape or sheet (wafer) form after removing the substrate. The surface roughness of these coatings is typically in the range $10 \mathrm{~nm}$ to $1 \mu \mathrm{m} R_{a}$ (centerline average) depending on the deposition conditions.

This chapter describes clean and contaminated diamond surfaces, CVD diamond film deposition technology, the characterization of CVD diamond film, and general and tribological properties of these films.

NASA/TM-1999-107249, Chapter 9 


\subsection{Diamond Surfaces}

\subsubsection{Clean Surface}

Because diamond has tetrahedral, covalent bonds between each atom and its four nearest neighbors, the free surface may expose dangling bonds. The free surface has high surface energy $\gamma$, which is associated with dangling bond formation.

Crystalline diamond and silicon all have the diamond structure, where each atom in the crystal is $\mathrm{sp}^{3}$ hybridized and tetrahedrally bonded to its four nearest neighbors. When the crystal is cut to expose a crystal plane, chemical bonds are broken along the plane, resulting in half-empty orbitals (dangling bonds) on the surface atoms [9.7, 9.8]. Because of the similarities between the bulk structures of diamond and silicon, a hypothetical surface structure of the silicon crystal, which is the ideal or bulk-terminated structure, is presented in Fig. 9.1 [9.7]. Simple counting of the

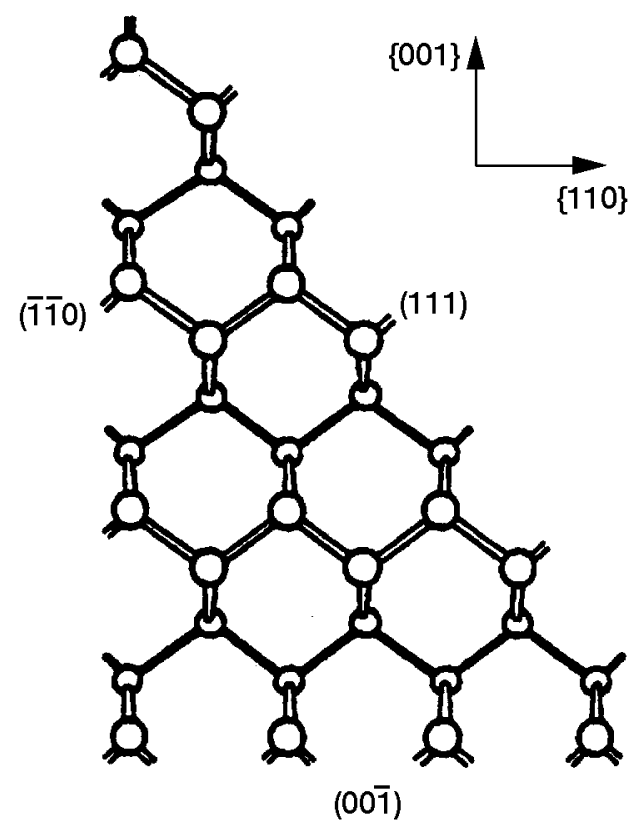

Figure 9.1.-Dangling bond formation on unreconstructed surfaces of (111), ( $(\overline{1} \overline{1} 0)$, and $(00 \overline{1})$ planes of silicon. (Each silicon atom in the bulk is bonded to its four nearest neighbors in a tetrahedral configuration. The sizes of the silicon atoms are shown to decrease away from the page. From [9.7].)

NASA/TM-1999-107249, Chapter 9 
broken bonds suggests that a surface atom will have two dangling bonds on the $\{00 \overline{1}\}$ plane but only one each on the $\{111\}$ and $\{\overline{1} 00\}$ planes, which are the energetically favored ones. Because of the high energy cost associated with dangling bond formation, most diamond surfaces will become reconstructed to reduce the number of dangling bonds, thus minimizing their surface free energy. The surface valency bonds will back-bond or rehybridize.

Researchers have found that atomically clean diamond has high adhesion and friction $[9.9,9.10]$. When a fresh atomically clean diamond surface comes in contact with an atomically clean surface of counterfacing material, the dangling bonds can form strong linkages with bonds on the counterfacing material surface. For example, if the surfaces of natural diamond and a metal are cleaned by argon ion bombardment, their coefficient of friction is higher than 0.4 , as described in Chapter 3 and [9.10]. With argon-sputter-cleaned diamond surfaces there are probably dangling bonds ready to link up directly with those of another surface.

Because diamond has the highest atomic density of any material, with a molar density of $0.293 \mathrm{~g}$-atom $/ \mathrm{cm}^{3}$, diamond is the stiffest, hardest, and least compressible of all substances. Tribologically, the real area of contact $A$ is small. Nevertheless, the adhesion and friction of diamond are high in ultrahigh vacuum if the interface is atomically clean and dangling bonds are ready to link up with the counterfacing material surface [9.9,9.10]. As discussed in Chapter 4, the adhesion and friction of materials are directly related to $s A$ or $\gamma A$. The dangling bonds, high shear strength $s$, and high surface energy $\gamma$ of a clean diamond surface not only provide high friction but also produce high diamond wear due to high adhesion in ultrahigh vacuum. This subject is discussed in Section 9.6.

\subsubsection{Contaminated Surface}

Although diamond is generally inert to most chemical environments, the interaction of hydrogen and oxygen with diamond surfaces may play an important role in the application of diamond film technology to tribology [9.9-9.11]. A clean diamond surface exposed to atomic hydrogen can adsorb the atomic hydrogen [9.12] and form a hydrogenated diamond surface. Figures 9.2 and 9.3 present a surface structural model for an as-grown $\{111\}$ diamond surface and an as-grown $\{100\}$ diamond surface, respectively [9.13]. Almost all carbon atoms on the $\{111\}$ surface are covered with methyl radical $\left(\mathrm{CH}_{3}\right)$ groups. The $\{100\}$ surface is terminated by the monohydride $(\mathrm{CH})$ group. The chemisorption of hydrogen on the dangling bonds preserves the $\mathrm{sp}^{3}$ hybridization of the surface carbon atoms and stabilizes the diamond structure against the formation of graphite. When a CVD diamond film is annealed to above $1050^{\circ} \mathrm{C}$, the surface hydrogen can be desorbed, destabilizing the diamond surface structure. Consequently, a nondiamond surface layer will be formed on the diamond surface [9.13-9.15].

Significant amounts of oxygen are present on both natural surfaces and those polished in an aqueous medium [9.16]. Oxygen can be chemically bonded to

NASA/TM-1999-107249, Chapter 9 


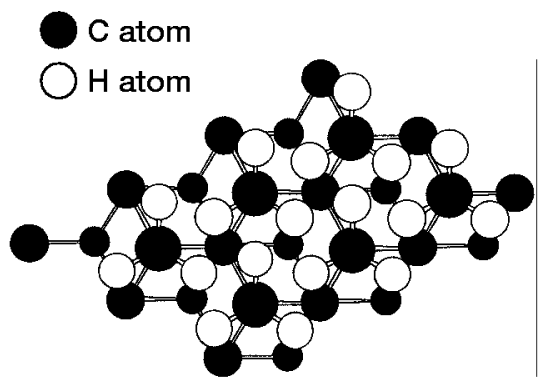

(a)

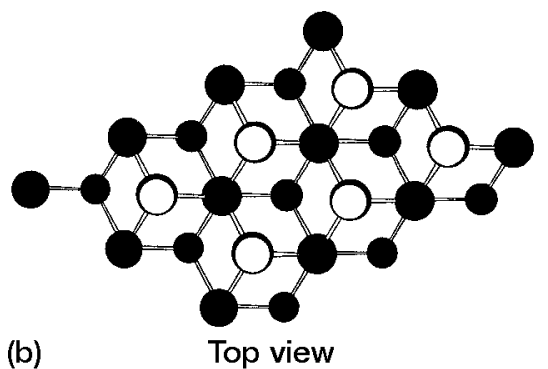

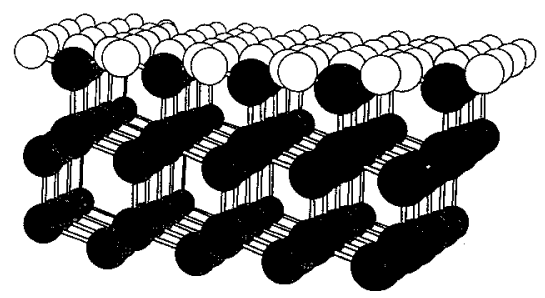

Side view

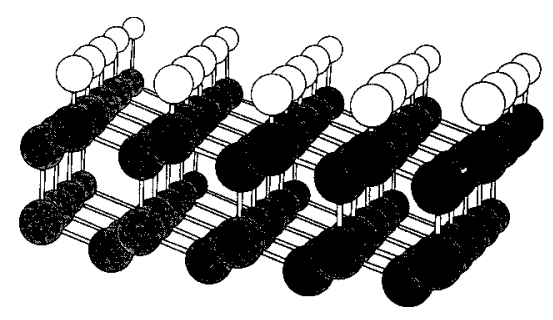

Side view

Figure 9.2.-Surface structural model for diamond $\{111\}$ surface. (The sizes of the carbon and hydrogen atoms are shown to decrease away from the page.) (a) Diamond $\{111\} 1 \times 1$ with $\mathrm{CH}_{3}$ (b) Diamond $\{111\} 1 \times 1$ with $\mathrm{CH}$.

diamond surfaces. A hydrogenated diamond surface oxidizes above $300^{\circ} \mathrm{C}$. The oxygen-containing surface species are desorbed as carbon monoxide and carbon dioxide above $480{ }^{\circ} \mathrm{C}$. Both oxygenation and desorption of oxygen-containing surface species simultaneously occur above $480^{\circ} \mathrm{C}$.

Both oxygen-terminated (oxidized) and hydrogen-terminated (hydrogenated) diamond surfaces provide low friction (see Section 9.6 for details). In the atmosphere diamond is known to be one of the slipperiest materials and is similar to polytetrafluoroethylene. This low friction is a surface property that apparently depends on the presence of adsorbed impurities, such as hydrocarbons from the atmosphere, on the oxidized and hydrogenated diamond surfaces.

Both oxidized and hydrogenated diamond surfaces can be fluorinated at temperatures from 300 to $1000^{\circ} \mathrm{C}$ when they are treated under carbon tetrafluoride $\left(\mathrm{CF}_{4}\right)$ plasma conditions $[9.16,9.17]$. The $\mathrm{C}-\mathrm{F}$ bond is observed on $\mathrm{CF}_{4}$-plasma-treated surfaces. Hydrogenated diamond surfaces fluorinate at lower temperatures than oxidized diamond surfaces. However, no fluorination occurs during thermal treatment 

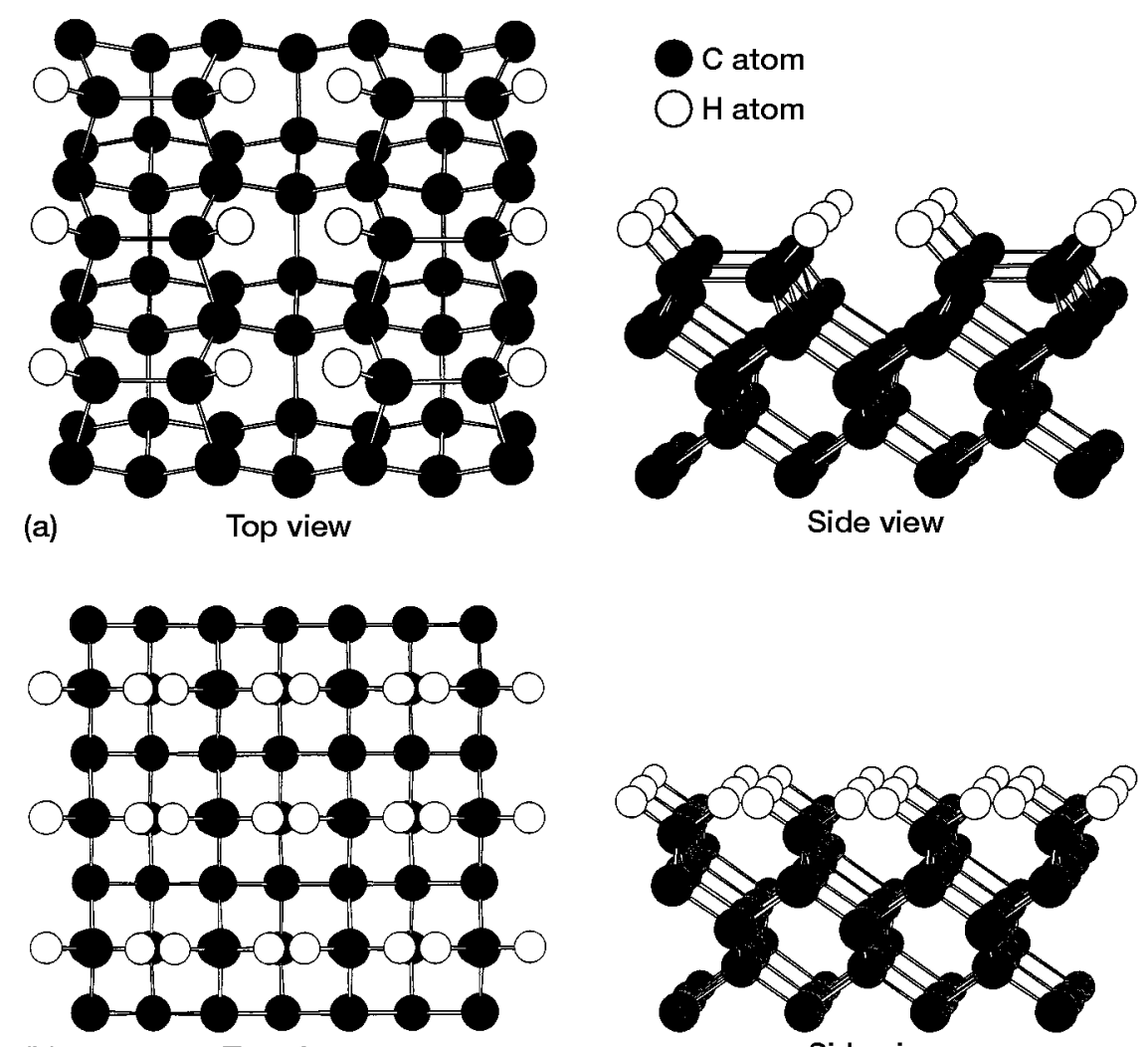

(b)

Top view

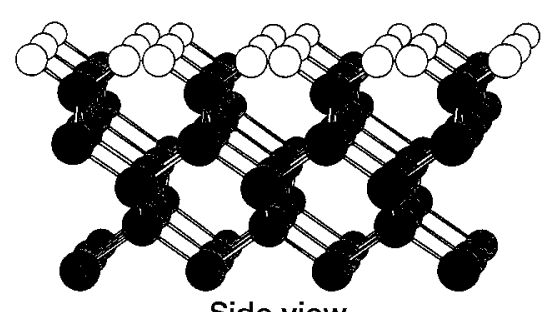

Figure 9.3.-Surface structural model for diamond $\{100\}$ surface. (The sizes of the carbon and hydrogen atoms are shown to decrease away from the page.) (a) Diamond \{100\} 2x1. (b) Diamond \{100\} $1 \times 1$.

in a $\mathrm{CF}_{4}$ environment. Plasma conditions, using $\mathrm{CF}_{4}$ as a reactant precursor, are necessary for fluorination.

On the other hand, the hydrogenated diamond surface is chlorinated by thermal reaction in chlorine [9.18]. Hydrogen chemisorbed on the diamond surface is abstracted by the chlorine, resulting in chlorine chemisorption. Water vapor can react with the chlorinated diamond surface even at room temperature, producing $\mathrm{O}-\mathrm{H}$ groups on the surface. A high-temperature treatment of chlorinated diamond with water further oxidizes the diamond surface, producing $\mathrm{C}=\mathrm{O}$ species on the surface. Water alone, however, cannot oxidize a hydrogenated diamond surface below $500^{\circ} \mathrm{C}$.

NASA/TM-1999-107249, Chapter 9 

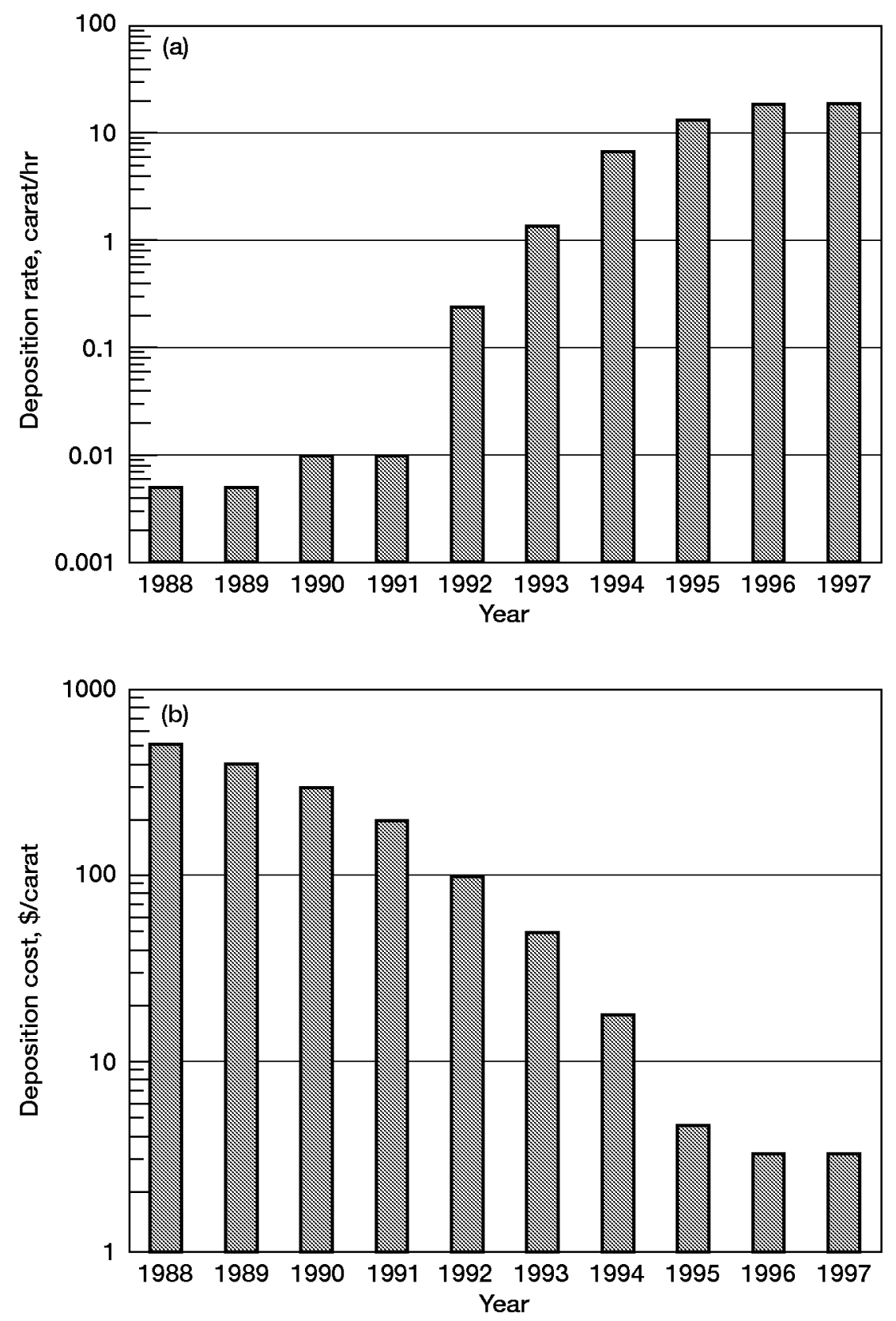

Figure 9.4.-Mass deposition rate increase and deposition cost reduction in past decade for CVD diamond produced by direct-current arc jet.

NASA/TM-1999-107249, Chapter 9 


\subsection{CVD Diamond Film Deposition Technology}

The basic reaction in the chemical vapor deposition of diamond is simple [9.12]. It involves the decomposition of a hydrocarbon, such as methane, as follows:

$$
\mathrm{CH}_{4} \rightarrow(\text { Activation }) \rightarrow \mathrm{C}(\text { diamond })+2 \mathrm{H}_{2}
$$

The carbon species must be activated, since at low pressure graphite is thermodynamically stable and, without activation, only graphite would be formed. Activation is obtained by two basic methods: high temperature and plasma, both of which require a great deal of energy.

Several CVD processes based on these two methods are presently in use. The four most important activation methods at this time are

1. High-frequency, plasma glow discharge using the microwave and radiofrequency processes

2. Plasma arcing using the direct-current arc and radiofrequency arc processes

3. Thermal CVD using the hot-filament process

4. Combustion synthesis using an oxyacetylene torch

Plasma arcing and combustion synthesis have high substrate deposition rates $[9.6,9.12]$. For example, the mass deposition rate using a direct-current arc jet was 20 carats/hr in 1997 (Fig. 9.4(a)). Progress in direct-current arc jet deposition has advanced to the point that the $\$ 5 /$ carat $\left(\$ 8 / \mathrm{cm}^{2}\right)$ barrier has been breached (Fig. 9.4(b)). In 1997 diamond made by direct-current arc jet was available at $\$ 8 / \mathrm{cm}^{2}\left(\$ 50 /\right.$ in. $\left.^{2}\right)$.

Diamond has been deposited from a large variety of precursors, including methane, aliphatic and aromatic hydrocarbons, alcohols, ketones, and solid polymers such as polyethylene, polypropylene, and polystyrene [9.12]. These substances generally decompose into two stable primary species: the methyl radicals $\left(\mathrm{CH}_{3}\right)$ and acetylene $\left(\mathrm{C}_{2} \mathrm{H}_{4}\right)$. The radical is the key compound in generating the growth of CVD diamond.

\subsection{Characterization of CVD Diamond}

A variety of techniques can be used to characterize CVD diamond films: scanning and transmission electron microscopy (SEM and TEM), to determine surface morphology, microstructure, and grain size; surface profilometry and scanning probe microscopy such as atomic force microscopy (AFM), to measure surface roughness and to determine surface morphology; Rutherford backscattering (RBS) and hydrogen forward scattering (proton recoil detection), to determine the composition including hydrogen; Raman spectroscopy, to characterize atomic bonding state and diamond quality; and x-ray diffraction, to determine the crystal orientation of diamond growth.

NASA/TM-1999-107249, Chapter 9 
It is generally accepted that, for a material to be recognized as diamond, it must have all of the following characteristics:

1. A clear, sharp diamond peak at $1332 \mathrm{~cm}^{-1}$ in the Raman spectrum

2. A crystalline morphology visible by SEM or TEM

3. A single-phase diamond crystalline structure detectable by $\mathrm{x}$-ray or electron diffraction

Examples as case studies have been prepared focusing attention primarily on microwave-plasma-assisted CVD diamond films and are described in the following subsections.

\subsubsection{Surface Morphology and Roughness}

The surface morphology and roughness of CVD diamond films can be controlled by varying the deposition parameters, such as gas-phase chemistry parameters and temperatures (e.g., see Table 9.1 and [9.19]). Figure 9.5 shows SEM photomicrographs of fine-, medium-, and coarse-grain diamond films. Triangular crystalline facets typical of diamond are clearly evident on the surfaces of the medium- and coarse-grain diamond films, which have grain sizes estimated at 1100 and $3300 \mathrm{~nm}$, respectively. The grain sizes of the fine-grain diamond were determined from bright- and dark-field electron photomicrographs to be between 20 and $100 \mathrm{~nm}$. The average surface roughness of the diamond films measured by a surface profilometer increases as the grain size increases, as shown in Fig. 9.6.

Note that Fig. 2.20(b) in Chapter 2 is an atomic force microscopy image of a finegrain CVD diamond film. The fine-grain diamond surface has a granulated or spherulitic morphology (i.e., the surface contains spherical asperities of different sizes).

TABLE 9.1.-DEPOSITION CONDITIONS FOR DIAMOND FILMS OF VARIOUS GRAIN SIZES
\begin{tabular}{|l|c|c|c|c|c|c|c|}
\hline \multicolumn{1}{|c|}{ Condition } & \multicolumn{7}{c|}{ Substrate } \\
\cline { 2 - 9 } & $\mathrm{Si}|100|$ & $\mathrm{Si} \mid 100\}$ & $\alpha-\mathrm{SiC}$ & $\alpha$-SiC & $\alpha$-SiC & $\mathrm{Si}_{3} \mathrm{~N}_{4}$ & $\mathrm{Si}_{3} \mathrm{~N}_{4}$ \\
\hline Deposition temperature, ${ }^{\circ} \mathrm{C}$ & $1015 \pm 50$ & $860 \pm 20$ & $1015 \pm 50$ & $965 \pm 50$ & $860 \pm 20$ & $965 \pm 50$ & $860 \pm 20$ \\
\hline Gaseous flow rate, $\mathrm{cm}^{3} / \mathrm{min}$ & & & & & & & \\
$\mathrm{CH}_{4}$ & 3.5 & 4 & 3.5 & 3.5 & 4 & 35 & 4 \\
$\mathrm{H}_{2}$ & 500 & 395 & 500 & 500 & 395 & 500 & 395 \\
$\mathrm{O}_{2}$ & 0 & 1 & 0 & 0 & 1 & 0 & 1 \\
\hline Pressure, torr & 40 & 5 & 40 & 40 & 5 & 40 & 5 \\
\hline Microwave power, $\mathrm{W}$ & 1000 & 500 & 1000 & 1000 & 500 & 1000 & 500 \\
\hline Deposition time, hr & 14 & 10.5 & 14 & 22 & 21 & 22 & 21 \\
\hline Thickness, $\mathrm{nm}$ & 4200 & 1000 & 5000 & 8000 & 1000 & 7000 & 800 \\
\hline Grain size, $\mathrm{nm}$ & 1100 & $20-100$ & 3300 & 1500 & $22-100$ & 1000 & $22-100$ \\
\hline Surface roughness rms, $\mathrm{nm}$ & 63 & 15 & 160 & 92 & 50 & 52 & 35 \\
\hline
\end{tabular}

${ }^{a}$ Scratched with $0.5-\mu \mathrm{m}$ diamond paste.

NASA/TM-1999-107249, Chapter 9 

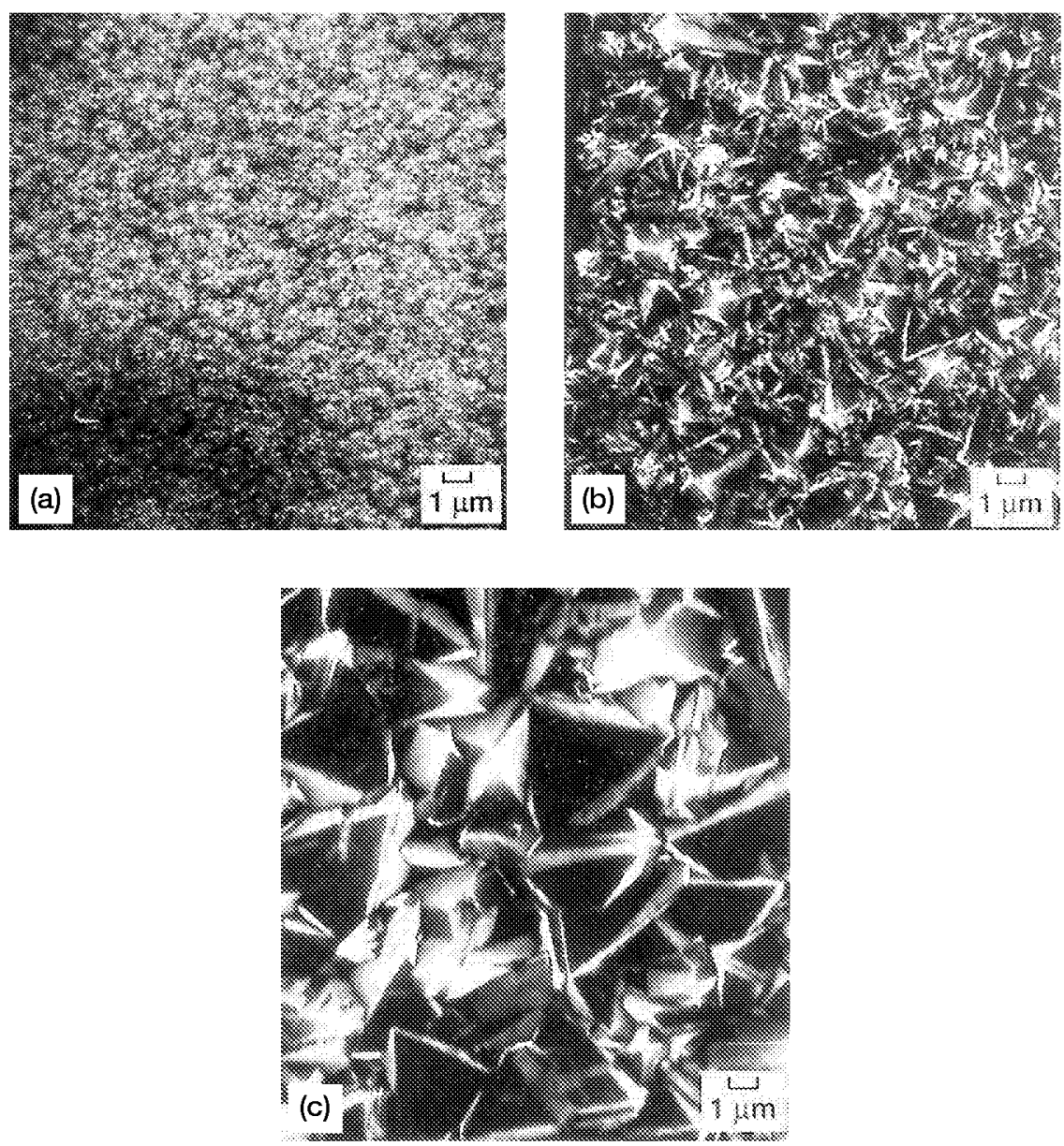

Figure 9.5.-Scanning electron micrographs of diamond films. (a) Fine-grain (20 to $100 \mathrm{~nm}$ ) diamond film on $\{100\}$ silicon substrate; rms surface roughness, $15 \mathrm{~nm}$. (b) Medium-grain (1100 nm) diamond film on $\{100\}$ silicon substrate; rms surface roughness, $63 \mathrm{~nm}$. (c) Coarse-grain (3300 nm) diamond film on $\{100\} \alpha$-silicon carbide substrate; rms surface roughness, $160 \mathrm{~nm}$.

\subsubsection{Composition}

Figures 9.7 and 9.8 [9.20] present a Rutherford backscattering spectrum and a hydrogen forward-scattering (HFS or proton recoil detection) spectrum, respectively, of the fine-grain CVD diamond film shown in Fig. 9.5(a). Besides carbon from the diamond film and silicon from the substrate, no other elements are

NASA/TM-1999-107249, Chapter 9 


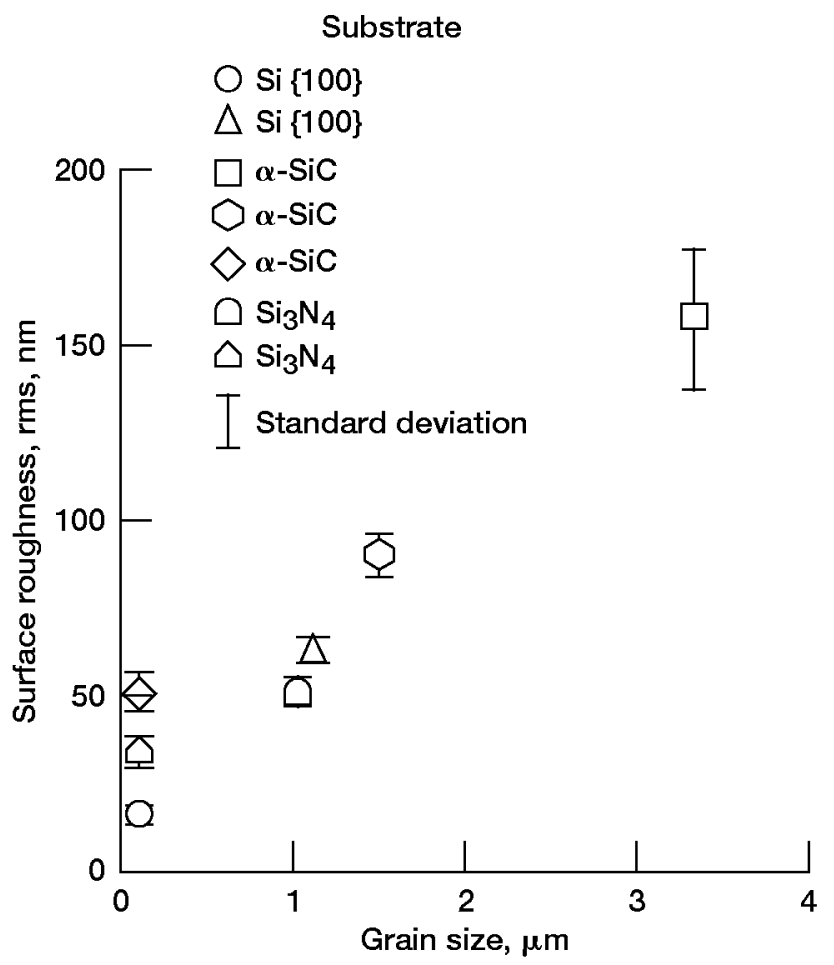

Figure 9.6.-Surface roughness as function of grain size for diamond films.

observed in the RBS spectrum. From both the RBS and HFS spectra it is estimated that the fine-grain diamond film consists of 97.5 at. \% carbon and 2.5 at. \% hydrogen. (In contrast, the medium- and coarse-grain diamond films contained less than 1 at. $\%$ hydrogen [9.19].) Both carbon and hydrogen are uniformly distributed in the finegrain diamond film from the top of the surface to the silicon substrate.

The RBS analytical results can also be used to determine diamond film thickness. Figure 9.7 also presents a simulated RBS spectrum of the fine-grain diamond film containing a carbon-to-hydrogen ratio $(\mathrm{C} / \mathrm{H})$ of $97.5 / 2.5$ obtained by using the RUMP computer code [9.21]. In the computer program the thickness of the diamond film is taken as a variable and is obtained from the close match between the observed and simulated RBS, as shown in Fig. 9.7. The film thickness of the fine-grain CVD diamond is $1.5 \mu \mathrm{m}$ at the center of the substrate, and the deposition rate is estimated to be $0.14 \mu \mathrm{m} / \mathrm{hr}$.

NASA/TM—1999-107249, Chapter 9 


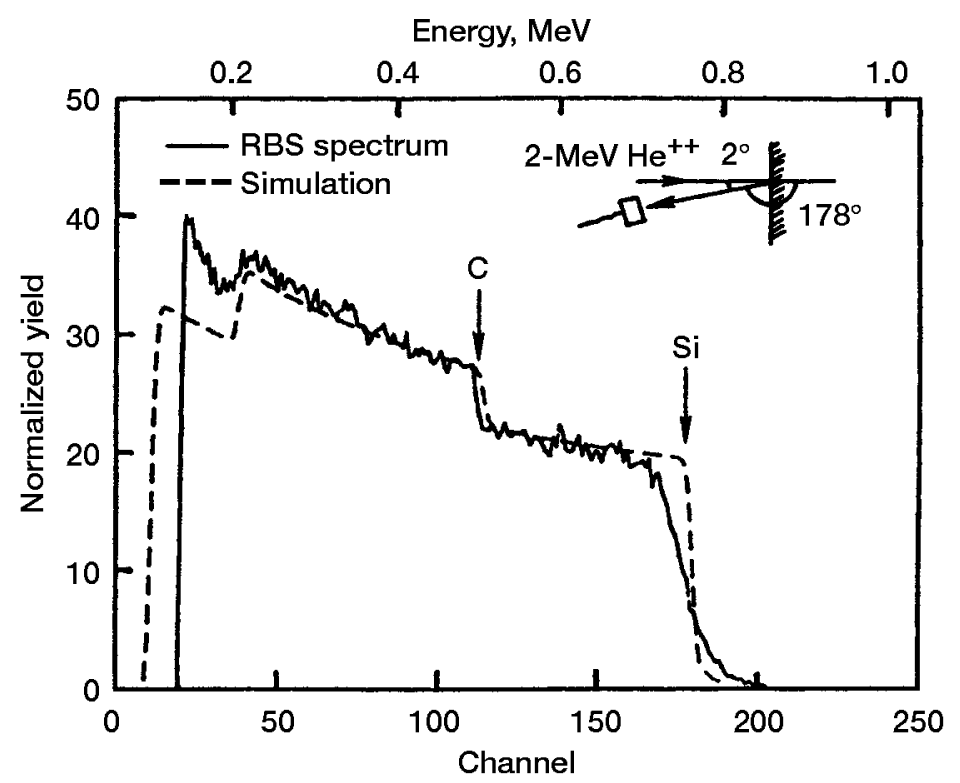

Figure 9.7.-Rutherford backscattering spectrum of fine-grain diamond film on silicon substrate. (Simulation curve was calculated by using the computer code RUMP.)

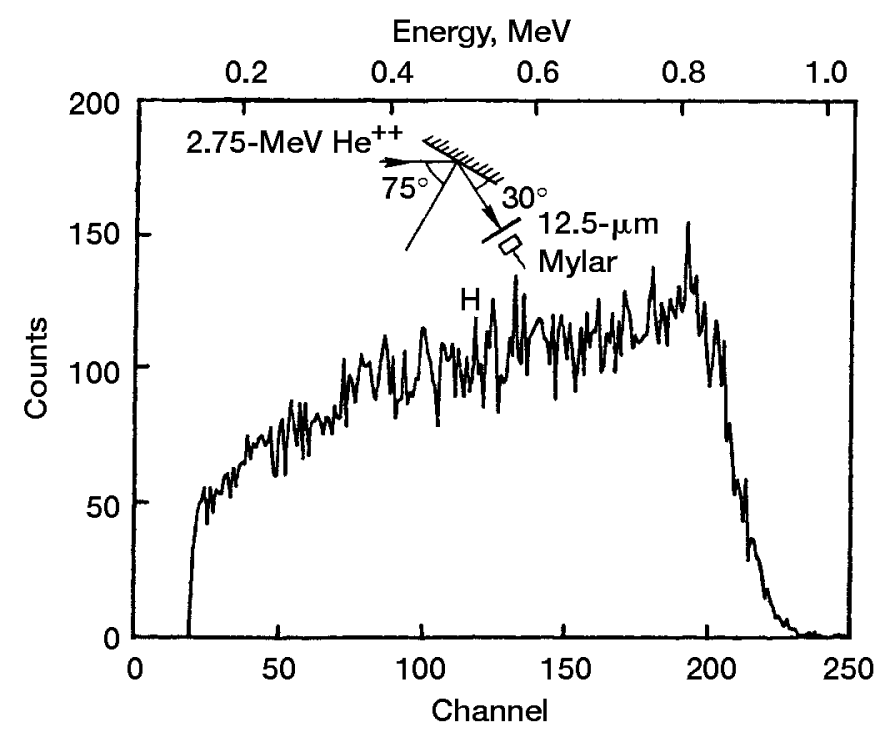

Figure 9.8.-Hydrogen forward-scattering spectrum (proton recoil analysis) of fine-grain diamond film on silicon substrate.

NASA/TM-1999-107249, Chapter 9 


\subsubsection{Atomic Bonding State}

Figure 9.9 shows typical Raman spectra of the fine- and medium-grain diamond films. Both spectra show one Raman band centered at $1332 \mathrm{~cm}^{-1}$ and one at 1500 to $1530 \mathrm{~cm}^{-1}$. The sharp peak at $1332 \mathrm{~cm}^{-1}$ is characteristic of the $\mathrm{sp}^{3}$ bonding of the diamond form of carbon in the film. The very broad peak centered around $1530 \mathrm{~cm}^{-1}$ is attributed to the $\mathrm{sp}^{2}$ bonding of the nondiamond forms of carbon (graphite and other forms of carbon) [9.22-9.24].

More diamond was produced in the medium-grain CVD diamond films (e.g., Fig. 9.9) than in the fine-grain films, as is evident from the relative intensities of the diamond and nondiamond carbon Raman bands [9.19]. However, the ratio of the intensities of the Raman responses at 1332 and $1530 \mathrm{~cm}^{-1}$ does not indicate the ratio of diamond to nondiamond carbon present in the film. The Raman technique is approximately 50 times more sensitive to $\mathrm{sp}^{2}$-bonded (nondiamond) carbon than it is to $\mathrm{sp}^{3}$-bonded (diamond) carbon [9.23]. Thus, the peak at approximately $1530 \mathrm{~cm}^{-1}$ for each film represents a much smaller amount of nondiamond carbon in these diamond films. The Raman spectrum of the coarse-grain diamond film was similar to that of the medium-grain diamond film.

\subsubsection{Microstructure}

$\mathrm{X}$-ray diffraction analysis (XRD) is used to determine the structure and crystal orientation of the CVD diamond films. Figure 9.10 shows typical XRD patterns for the fine- and medium-grain diamond films [9.19]. Peaks representing only the diamond film and the silicon substrate appear in the XRD spectra. Diffraction peaks corresponding to the $\{111\},\{220\},\{311\}$, and $\{400\}$ planes, reflective of diamond, are clearly evident. The intensity ratios $I\{220\} / I\{111\}$ were calculated from the XRD patterns for the fine- and medium-grain diamond films and found to be 1.3 and 0.04 , respectively. The powder diffraction pattern of diamond with random crystal orientation (ASTM 6-0675) gives $I\{220\} / I\{111\}=0.27$.

Thus, most crystallites in the fine-grain diamond film are oriented along the $\langle 110\rangle$ direction. Other researchers [9.22] have observed similar $\{110\}$ crystal orientation texture in microcrystalline diamond film grown in a $\{100\}$ silicon substrate by an activated CVD technique. Most crystallites in the medium-grain diamond films are oriented along the $\langle 111\rangle$ direction, and the $\{111\}$ planes are parallel to the surface. The well-formed triangular facets observed in SEM photomicrographs (Fig. 9.5) of the medium- and coarse-grain diamond films confirm the $\langle 111\rangle$ crystal orientation.

Figure 9.11 presents the transmission electron diffraction pattern, a transmission electron bright-field photomicrograph, and a transmission electron dark-field photomicrograph of the free-standing, fine-grain CVD diamond film [9.20]. Diffraction rings and dots are observed in the selected-area diffraction (SAD) pattern (Fig. 9.11(a)). The $d$ spacings of the diffraction rings were calculated by using an

NASA/TM—1999-107249, Chapter 9 

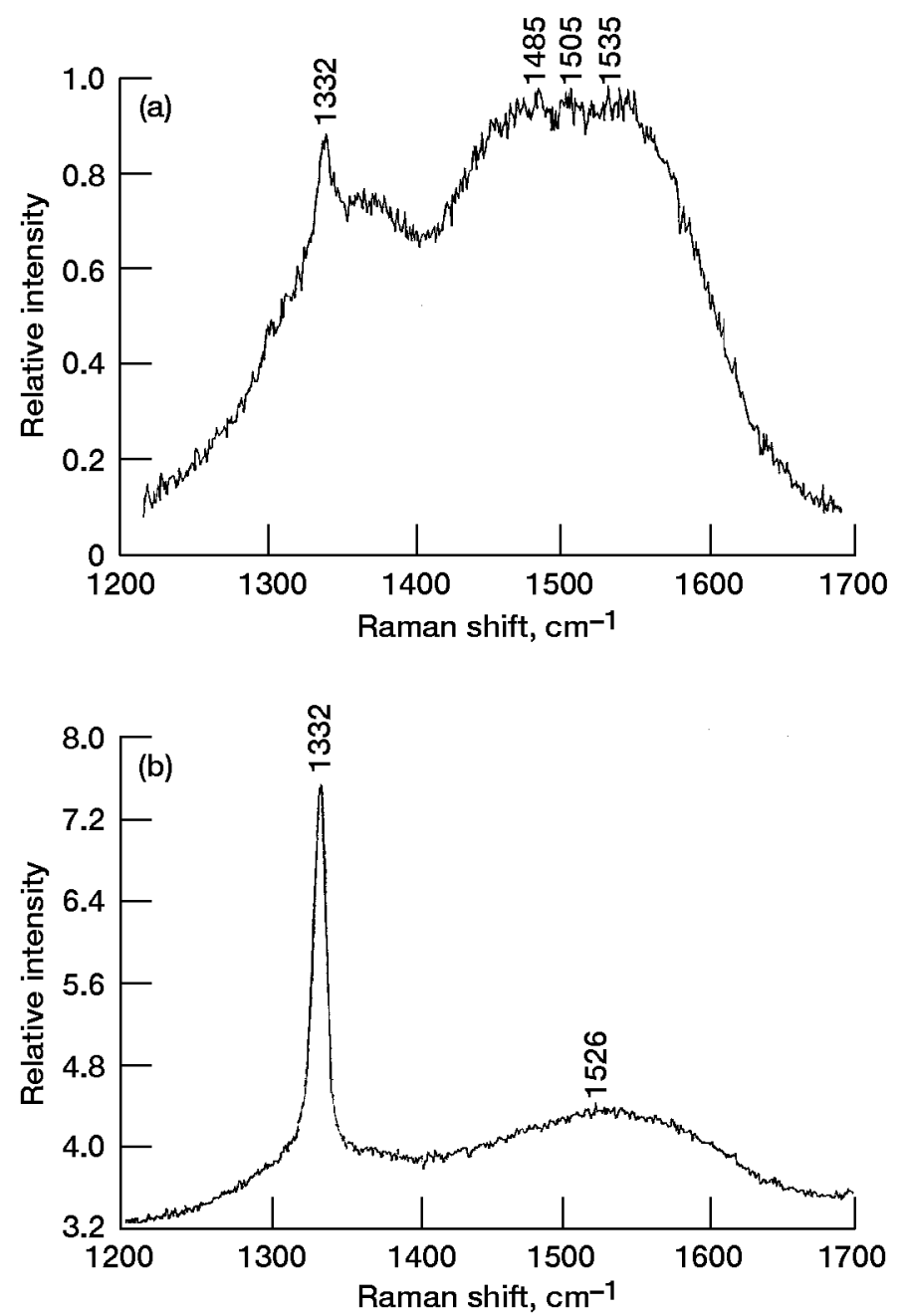

Figure 9.9.-Raman spectra of diamond films. (a) Fine-grain (20 to $100 \mathrm{~nm}$ ) diamond film on $\{100\}$ silicon substrate.

(b) Medium-grain $(1100 \mathrm{~nm})$ diamond film on $\{100\}$ silicon substrate.

NASA/TM-1999-107249, Chapter 9 

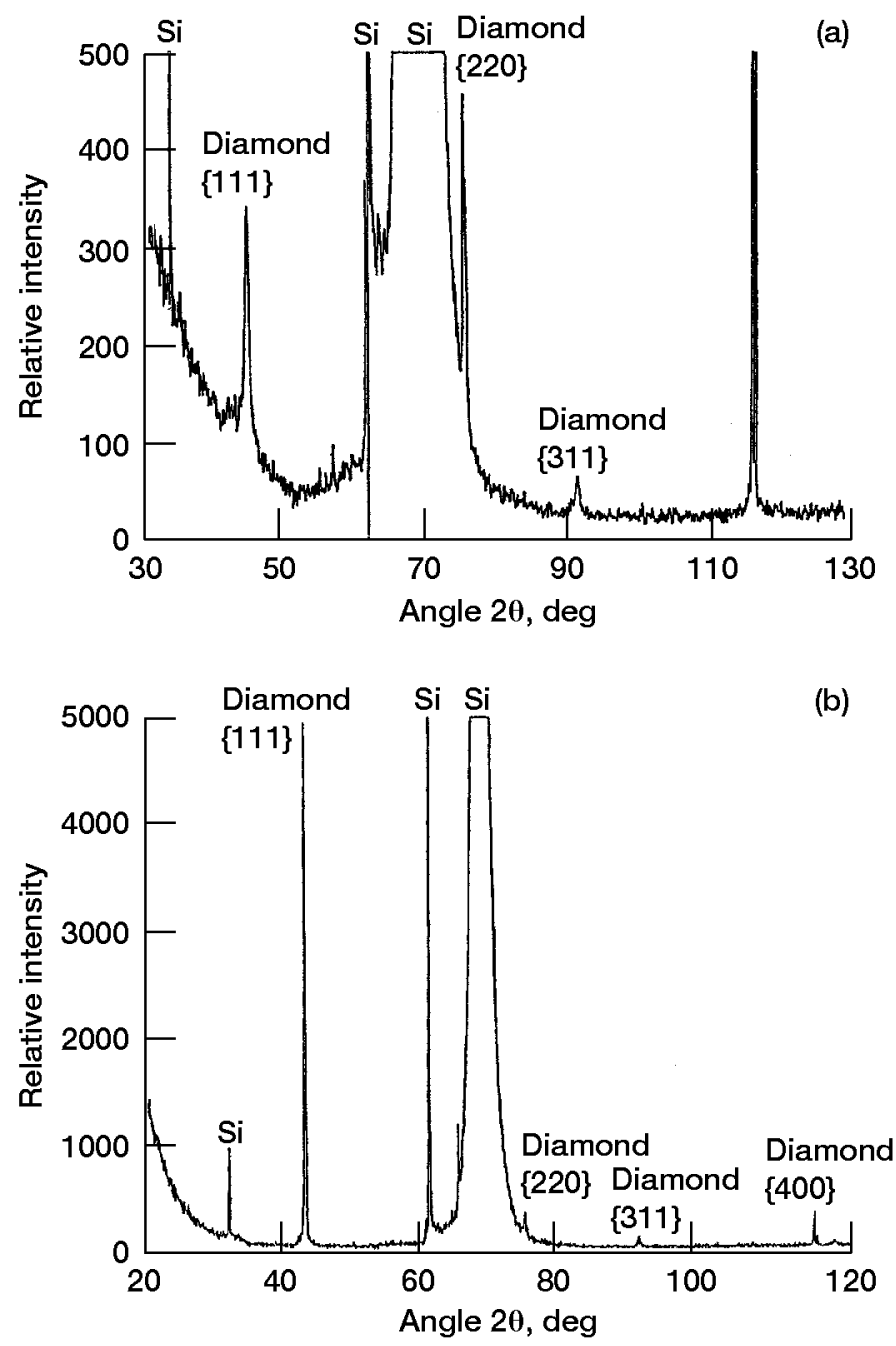

Figure 9.10.-X-ray diffraction patterns of diamond films. (a) Fine-grain (20 to $100 \mathrm{~nm}$ ) diamond film on $\{100\}$ silicon substrate. (b) Medium-grain (1100 nm) diamond film on $\{100\}$ silicon substrate.

NASA/TM—1999-107249, Chapter 9 

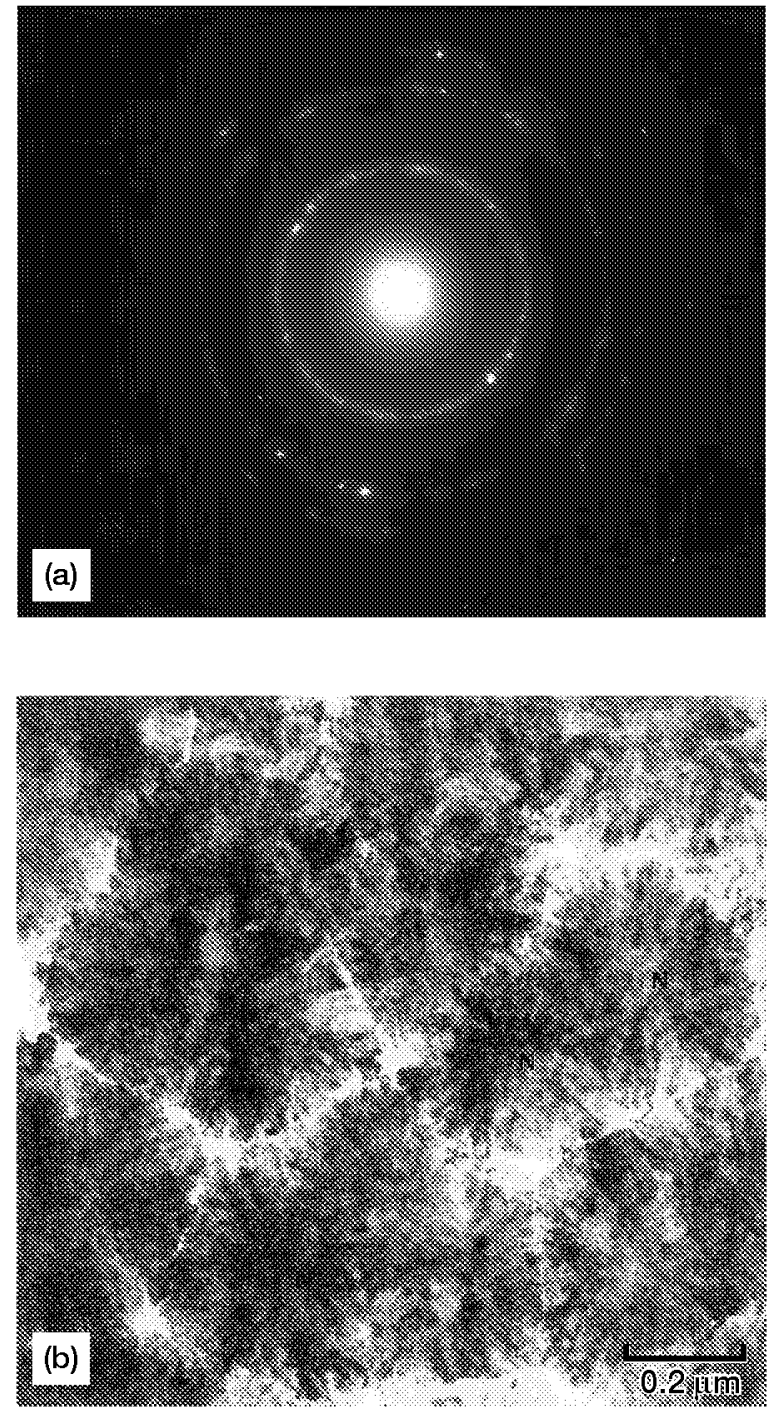

Figure 9.11.-Free-standing diamond films.

(a) Selected-area diffraction pattern.

(b) Bright-field TEM. (c) Dark-field TEM.

NASA/TM-1999-107249, Chapter 9 


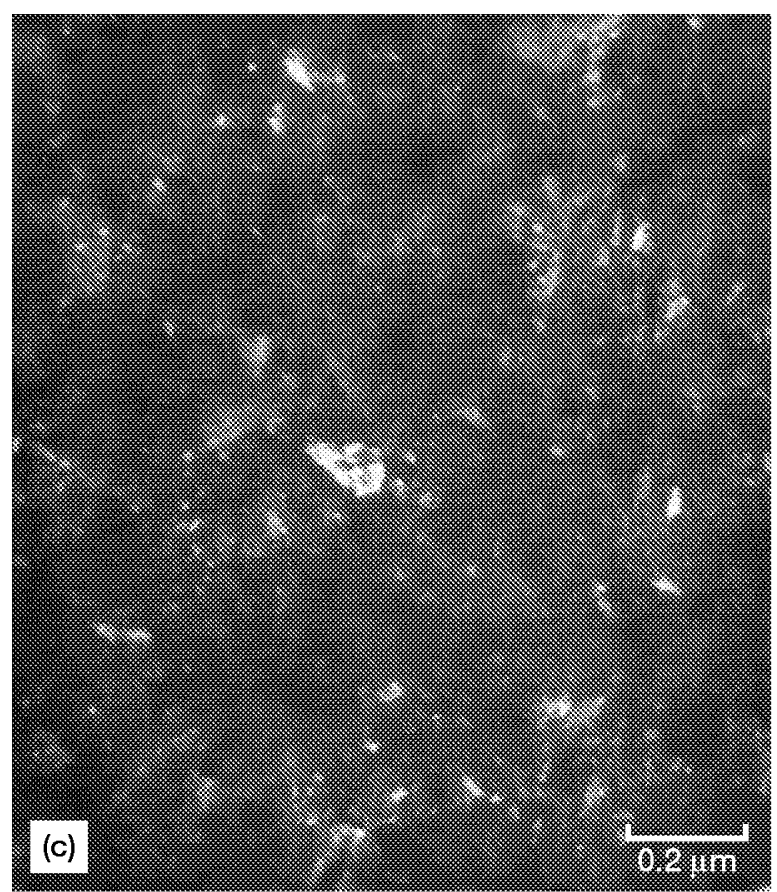

Figure 9.11.-Concluded. (c) Dark-field TEM.

aluminum SAD pattern as a calibration standard and found to match well with the known diamond d spacings. No evidence of nondiamond carbon is found in the SAD pattern. This observation indicates that the concentration of nondiamond component in the diamond film is very small.

Careful observation of the bright-field photomicrograph (Fig. 9.11(b)) shows various nuclei-like regions marked N. Diamond grains are distributed radially outward from these nuclei. A grain boundary is formed where the grains from various nuclei meet. The grain sizes were estimated from the dark-field photomicrograph (Fig. 9.11(c)) and found to vary from 20 to $100 \mathrm{~nm}$.

\subsection{General Properties of CVD Diamond}

Diamond consists of light carbon atoms held together by strong forces, and this combination produces many extreme properties. Table 9.2 summarizes the general properties of CVD diamond and compares them to those of single-crystal diamond, such as type $\mathrm{Ib}$. This table and the description in this section are based on a table from Pierson [9.12] and other references [9.25-9.27]. Because of the difficulty in testing, the effect of impurities and structural defects, and the differences between the various deposition processes, uncertainty and spread have been found in the reported property values. The values in Table 9.2 should be viewed with caution.

NASA/TM-1999-107249, Chapter 9 
TABLE 9.2.-PROPERTIES OF CVD DIAMOND

\begin{tabular}{|c|c|c|}
\hline Property & CVD diamond & Single-crystal diamond \\
\hline Density, $\mathrm{g} / \mathrm{cm}^{3}$ & 3.51 & 3.515 \\
\hline $\begin{array}{l}\text { Thermal conductivity at } 25^{\circ} \mathrm{C} \text {, } \\
\qquad \mathrm{W} \mathrm{m}{ }^{-1}{ }^{\circ} \mathrm{C}^{-1}\end{array}$ & 2100 & 2200 \\
\hline $\begin{array}{l}\text { Thermal expansion coefficient at } 25 \text { to } \\
200^{\circ} \mathrm{C},{ }^{\circ} \mathrm{C}^{-1}\end{array}$ & $2.0 \times 10^{6}$ & $(1.5$ to 4.8$) \times 10^{6}$ \\
\hline Tensile strength, GPa & 1 to 5 & 4 to 6 \\
\hline Young's modulus, $\mathrm{Pa}$ & $(7$ to 9$) \times 10^{11}$ & $10.5 \times 10^{11}$ \\
\hline Poisson's ratio, GPa & 0.1 or 0.07 & 0.1 or 0.07 \\
\hline Vicker's hardness range, ${ }^{\mathrm{a}} \mathrm{kg} / \mathrm{mm}^{3}$ & 5000 to 10000 & 5700 to 10400 \\
\hline Chemical properties & \multicolumn{2}{|c|}{$\begin{array}{l}\text { Both CVD sand single-crystal diamonds } \\
\text { are resistant to all liquid organic and } \\
\text { inorganic acids, alkalis, and solvents at } \\
\text { room temperature. One of the most } \\
\text { chemically resistant materials. }\end{array}$} \\
\hline Band gap, eV & 5.45 & 5.45 \\
\hline Index of refraction at $10 \mu \mathrm{m}$ & 2.34 to 2.42 & 2.40 \\
\hline Electrical resistivity, ohm $\cdot \mathrm{cm}$ & $10^{12}$ to $10^{16}$ & $10^{16}$ \\
\hline Dielectric constant $(45 \mathrm{MHz}$ to $20 \mathrm{GHz})$ & 5.6 & 5.70 \\
\hline Dielectric strength, $\mathrm{V} / \mathrm{cm}$ & $10^{6}$ & $10^{6}$ \\
\hline Loss tangent (45 $\mathrm{MHz}$ to $20 \mathrm{GHz}$ ) & $<0.0001$ & 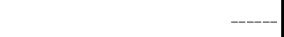 \\
\hline Saturated electron velocity & 2.7 & 2.7 \\
\hline Carrier mobility: & & \\
\hline Electron (n) & 1350 to 1500 & 2200 \\
\hline Positive hole (p) & 480 & 1600 \\
\hline
\end{tabular}

In diamond the light carbon atoms are densely packed, but the lattice is in many ways similar to those of other crystals, such as silicon, of the same structure. Therefore, diamond is a lightweight material, the density of both CVD diamond and single-crystal diamond being approximately $3.5 \mathrm{~g} / \mathrm{cm}^{3}$ (Table 9.2). Note that the closeness of carbon atoms leads to a small compressibility, as described in Chapter 8, and the specific heat is also small $\left(6.19 \mathrm{~J} \mathrm{~g}\right.$-atom $\left.^{-1}{ }^{\circ} \mathrm{C}^{-1}\right)$ at room temperature).

One of the many remarkable properties of diamond is its high thermal conductivity, as shown in Fig. 9.12. The data in this figure were taken from Pierson [9.12] and Windischmann [9.6]. For the highest quality single-crystal, type IIa diamonds the thermal conductivity is about $25 \mathrm{~W} \mathrm{~cm}^{-1}{ }^{\circ} \mathrm{C}^{-1}$ at room temperature, or more than six times that of copper $\left(4 \mathrm{~W} \mathrm{~cm}^{-1}{ }^{\circ} \mathrm{C}^{-1}\right)$. Such high thermal conductivity is caused by the stiffness of the diamond bond and the diamond structure. Other types of single-crystal diamond and CVD diamond have lower thermal conductivity (Table 9.2) at room temperature because they contain larger concentrations of impurities than does type IIa diamond.

Using values of $10.5 \times 10^{11} \mathrm{~Pa}, 5.5 \times 10^{11} \mathrm{~Pa}, 5.3 \mathrm{~J} / \mathrm{m}$, and $0.154 \mathrm{~nm}$ for the Young's modulus, the shear modulus, the fracture surface energy, and the nearest neighbor distance, respectively, the theoretical strength in tension of single-crystal diamond is $1.9 \times 10^{11} \mathrm{~Pa}$ in the $\langle 111\rangle$ direction (i.e., $\sim E / 5$, where $E$ is the modulus of elasticity [9.25]). Theoretical strength in shear equals $12.1 \times 10^{10} \mathrm{~Pa}$ in the $\langle 110\rangle\{111\}$ system

NASA/TM—1999-107249, Chapter 9 


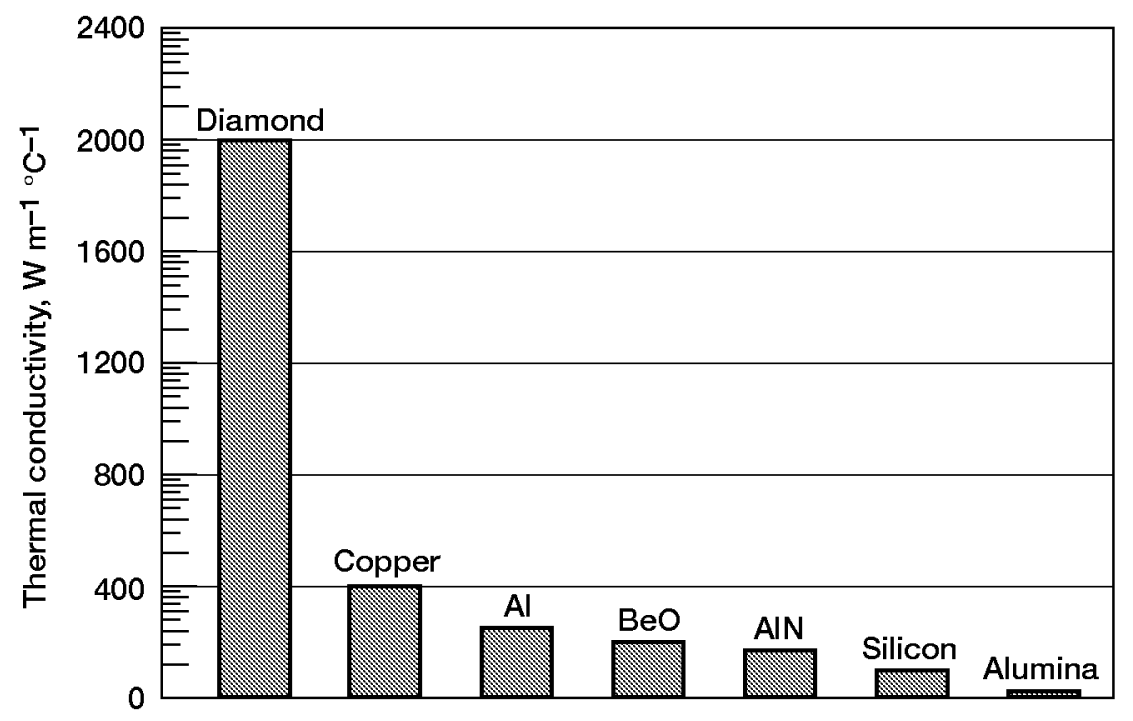

Figure 9.12.-Thermal conductivity of CVD diamond and other materials.

(i.e., $\sim G / 4$, where $G$ is the shear modulus). Actual tensile strengths for the octahedral $\{111\}$ and cubic $\{100\}$ planes of single-crystal type IIa diamond are 3.8 and $3.7 \mathrm{GPa}$, respectively. The average is $\sim 3.75 \mathrm{GPa}$ for a Poisson's ratio of 0.1 (or $\sim 4.0 \mathrm{GPa}$ for a Poisson's ratio of 0.07 ), roughly $1 / 50$ th of the theoretical strength. Actual tensile strengths obtained by many workers range from 4 to $6 \mathrm{GPa}$ for singlecrystal diamond and from 1 to $5 \mathrm{GPa}$ for CVD diamond (Table 9.2). Many workers have found Young's moduli for CVD diamond in the range $7 \times 10^{11}$ to $9 \times 10^{11} \mathrm{~Pa}$ and Poisson's ratios of 0.1 or 0.07 [9.25-9.27].

Chapter 8 states that diamond is the hardest known material and that the hardness of single-crystal diamond varies by a factor 2 or more as a function of crystal orientation and impurities. This statement is also true for CVD diamond. Figure 9.13, based on a figure from [9.12] and other references [9.25-9.30], shows the high indentation hardness for diamond as compared with a few other hard materials.

Diamond is chemically resistant to all liquid organic and inorganic acids at room temperature. However, it can be etched by several compounds, including strong oxidizers such as sodium and potassium nitrates above $500^{\circ} \mathrm{C}$, by fluxes of sodium and potassium chlorates, and by molten hydroxides, such as sodium hydroxide $(\mathrm{NaOH})$. Diamond is resistant to alkalis and solvents. At approximately $1000^{\circ} \mathrm{C}$ it reacts readily with carbide-forming metals such as iron, cobalt, nickel, aluminum, tantalum, and boron. Generally speaking, diamond can be considered as one of the most chemical-resistant materials. The chemical properties of CVD diamond are similar to those of single-crystal diamond.

NASA/TM—1999-107249, Chapter 9 


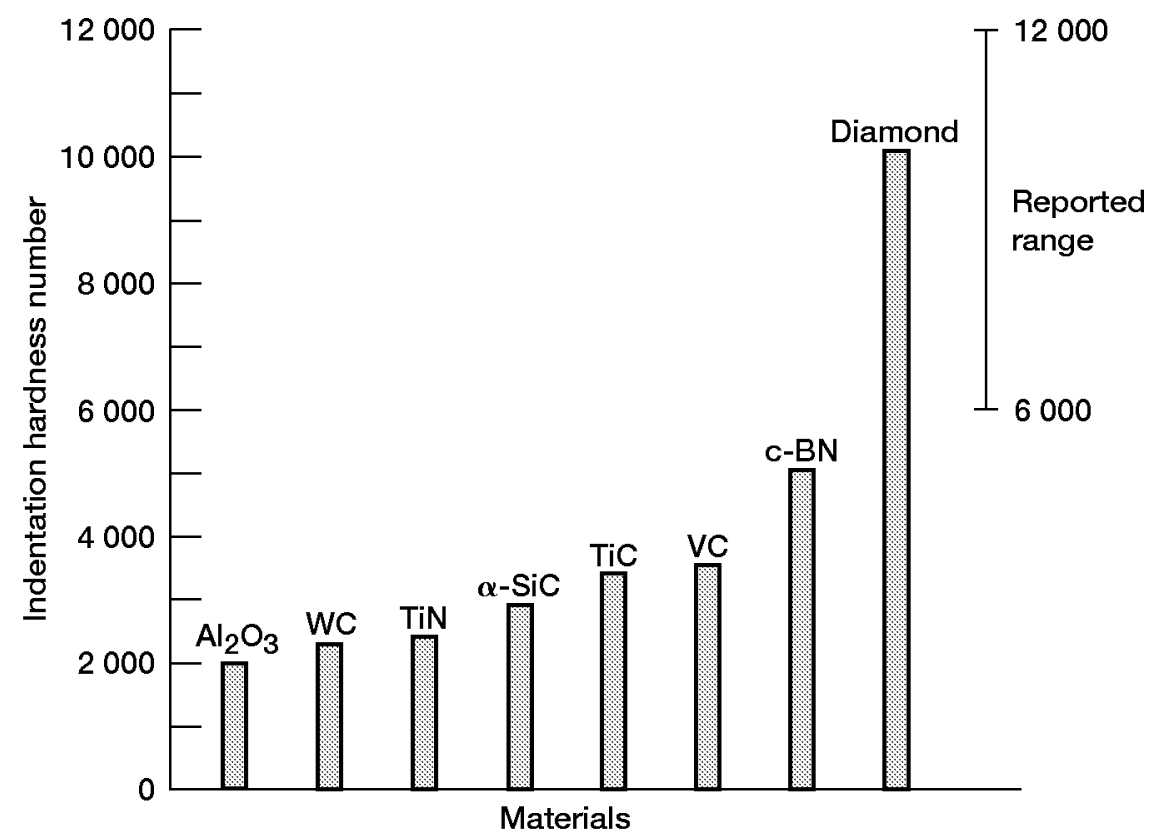

Figure 9.13.-Indentation hardness of diamond and other hard materials.

Table 9.2 also includes optical, electrical, and semiconductor properties of diamond as a reference.

\subsection{Friction and Wear Properties of CVD Diamond}

\subsubsection{Humid Air and Dry Nitrogen Environments}

The tribological properties of CVD diamond are similar to those of natural and synthetic diamond. The coefficient of friction and wear resistance of CVD diamond are generally superior in the atmosphere. However, the environment to which a CVD diamond film is exposed can markedly affect its tribological properties, such as friction and wear behavior. They vary with the environment, possessing a Jekylland-Hyde character [9.19].

When the fine-, medium-, and coarse-grain diamond films characterized in Section 9.4 were brought into contact with a natural diamond pin in reciprocating sliding motion in air and in nitrogen, the coefficients of friction varied as the pin traveled back and forth (reciprocating motion), retracing its tracks on the diamond films (Fig. 9.14).

NASA/TM—1999-107249, Chapter 9 

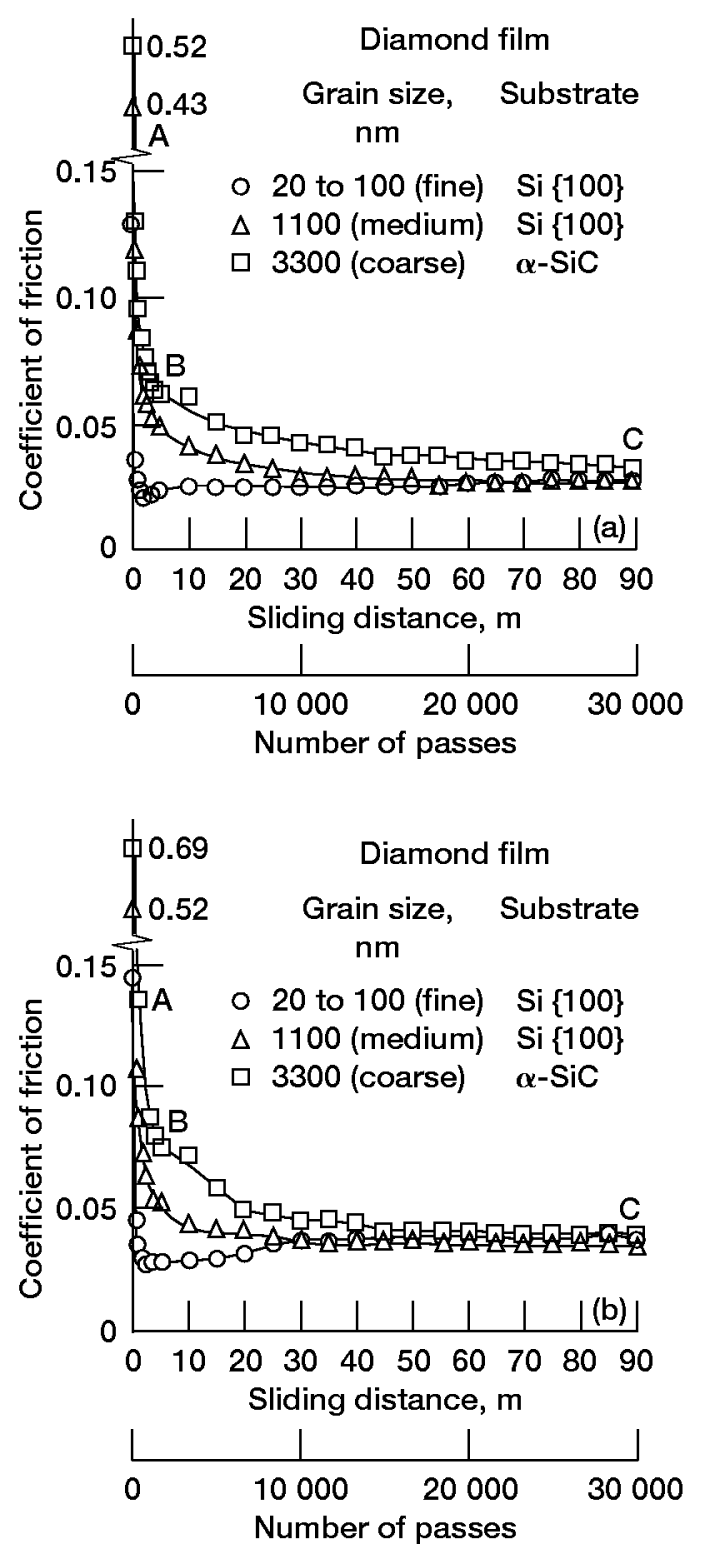

Figure 9.14.-Coefficient of friction as function of number of passes of bulk diamond pin in contact with fine-, medium-, and coarsegrain diamond films (a) in humid air (approx. $40 \%$ relative humidity) and (b) in dry nitrogen.

NASA/TM-1999-107249, Chapter 9 
Both in humid air at a relative humidity of $40 \%$ and in dry nitrogen, abrasion occurred and dominated the friction and wear behavior. The bulk natural diamond pin tended to dig into the surface of diamond films during sliding and produce a wear track (groove). SEM observations of the diamond films indicated that small fragments chipped off their surfaces. When abrasive interactions between the diamond pin surface and the initially sharp tips of asperities on the diamond film surfaces were strong, the friction was high (points A in Fig. 9.14). The surface roughness of diamond films can have an appreciable influence on their initial friction (i.e., the greater the initial surface roughness, the higher the initial coefficient of friction, Fig. 9.15(a)). Similar frictional results have also been found by other workers on single-crystal diamonds [9.31] and on diamond coatings [9.32-9.34].

As sliding continued and the pin passed repeatedly over the same track, the coefficient of friction was appreciably affected by the wear on the diamond films (Fig. 9.14) (i.e., a blunting of the tips of asperities). When repeated sliding produced a smooth groove or a groove with blunted asperities on the diamond surface (Fig. 9.16), the coefficient of friction was low, and the initial surface roughness effect became negligible. Therefore, the equilibrium coefficient of friction was independent of the initial surface roughness of the diamond film (Fig. 9.15(b)).

The generally accepted wear mechanism for diamonds is that of small fragments chipping off the surface $[9.9,9.19]$. This mechanism is in agreement with the wear of diamond films. The wear rate is dependent on the initial surface roughness of the diamond films (Fig. 9.17), increasing markedly with an increase in initial surface roughness. The wear rates of the diamond films in humid air and in dry nitrogen are comparable to the wear rates of single-crystal diamonds and diamond films investigated by other workers $[9.32,9.35,9.36]$.

\subsubsection{Ultra-High-Vacuum Environment}

When the fine-, medium-, and coarse-grain diamond films were brought into contact with a natural diamond pin in unidirectional pin-on-disk sliding motion in vacuum, the coefficients of friction were high and varied with the number of passes [9.15]. In vacuum, as in humid air and in dry nitrogen, the bulk natural diamond pin dug into the surfaces of the diamond films during sliding and produced a wear track (groove, Fig. 9.18). The groove surface was generally smoother than the original surface of the diamond films. Further analysis of the grooves by scanning electron microscopy revealed that the tips of the diamond coating asperities were worn smooth and that the gaps between asperities were filled by debris.

The coefficient of friction increased with an increase in the number of passes (Fig. 9.19), just the opposite of what occurred in humid air and in dry nitrogen. Further, the initial surface roughness of the diamond film had no effect on friction. These results lead us to ask the following questions: What factors determine friction behavior? Have dangling bonds been exposed during sliding and played a role in the

NASA/TM—1999-107249, Chapter 9 

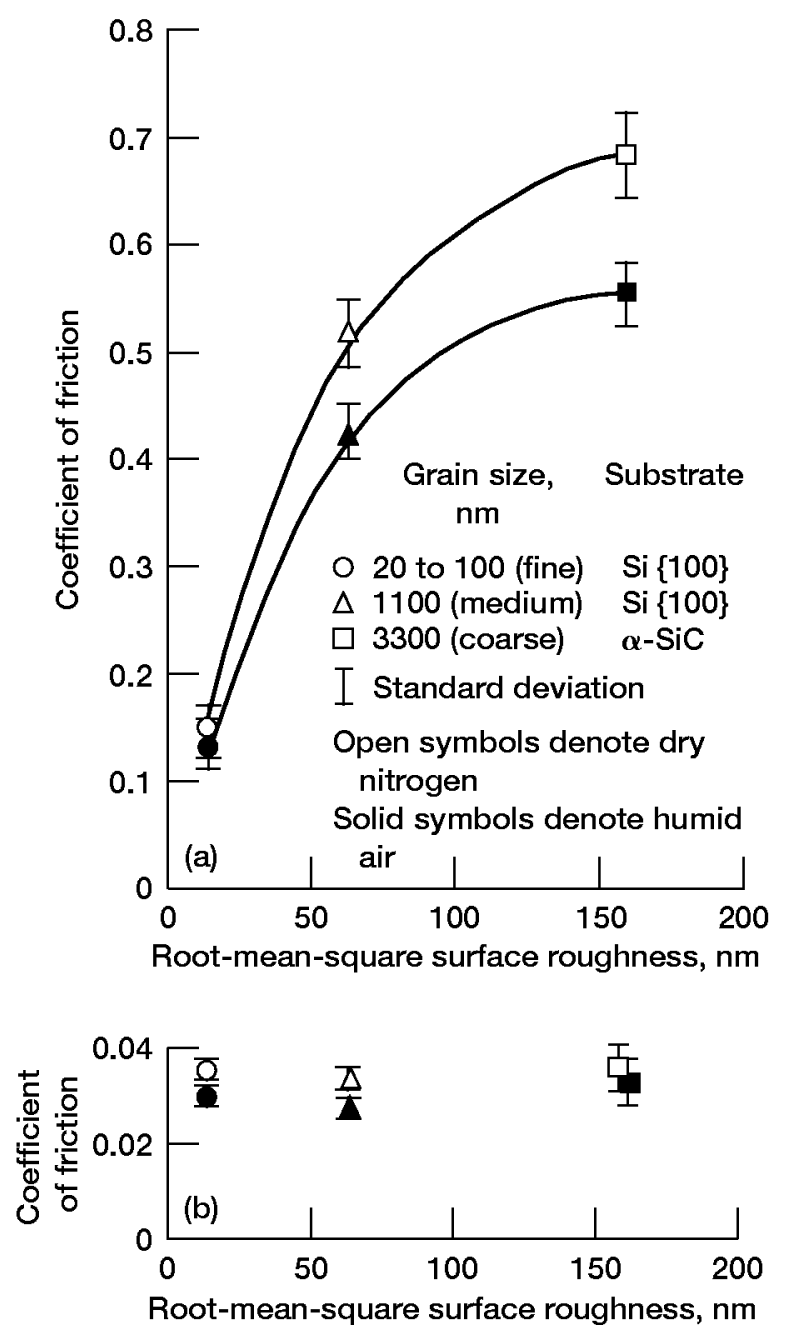

Figure 9.15.-Coefficient of friction as function of initial surface roughness of diamond films in humid air (approx. 40\% relative humidity) and in dry nitrogen. (a) Initial coefficients of friction. (b) Equilibrium coefficients of friction.

NASA/TM—1999-107249, Chapter 9 


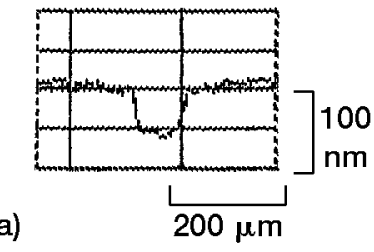

(b)

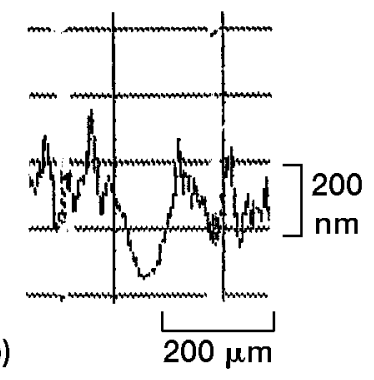

(c)

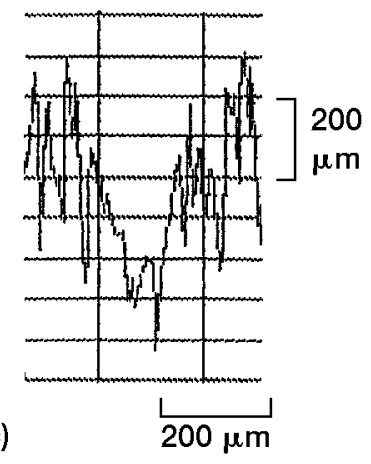

Figure 9.16.-Wear tracks (grooves) on diamond films after 30000 passes of bulk diamond pin in dry nitrogen. (a) Fine-grain (20 to $100 \mathrm{~nm}$ ) diamond film; rms surface roughness, $15 \mathrm{~nm}$. (b) Medium-grain (1100 nm) diamond film; rms surface roughness, $63 \mathrm{~nm}$. (c) Coarsegrain $(3300 \mathrm{~nm})$ diamond film; rms surface roughness, $160 \mathrm{~nm}$.

NASA/TM—1999-107249, Chapter 9 


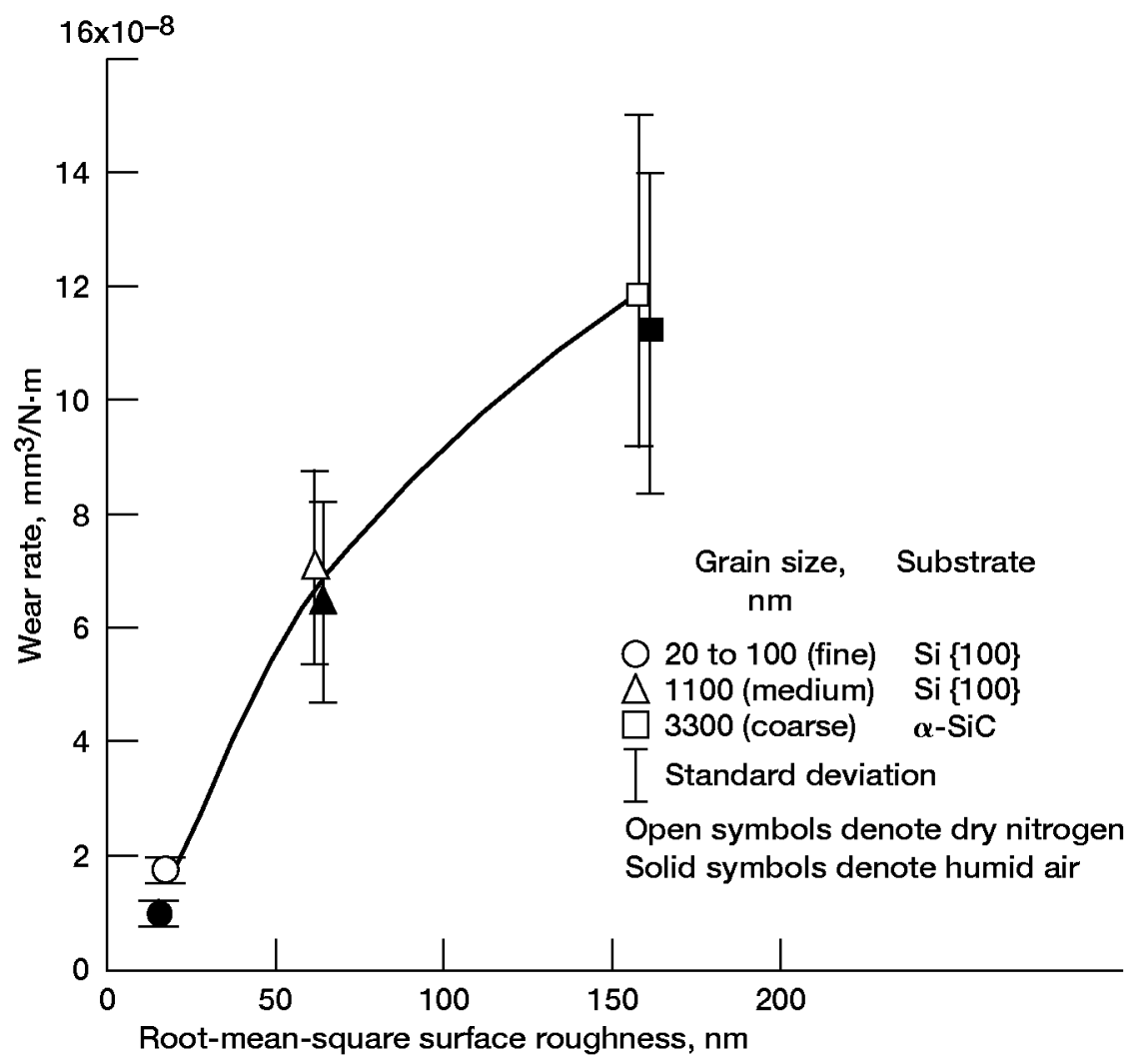

Figure 9.17.-Wear rates of diamond films as function of diamond surface roughness in humid air and in dry nitrogen.

NASA/TM-1999-107249, Chapter 9 

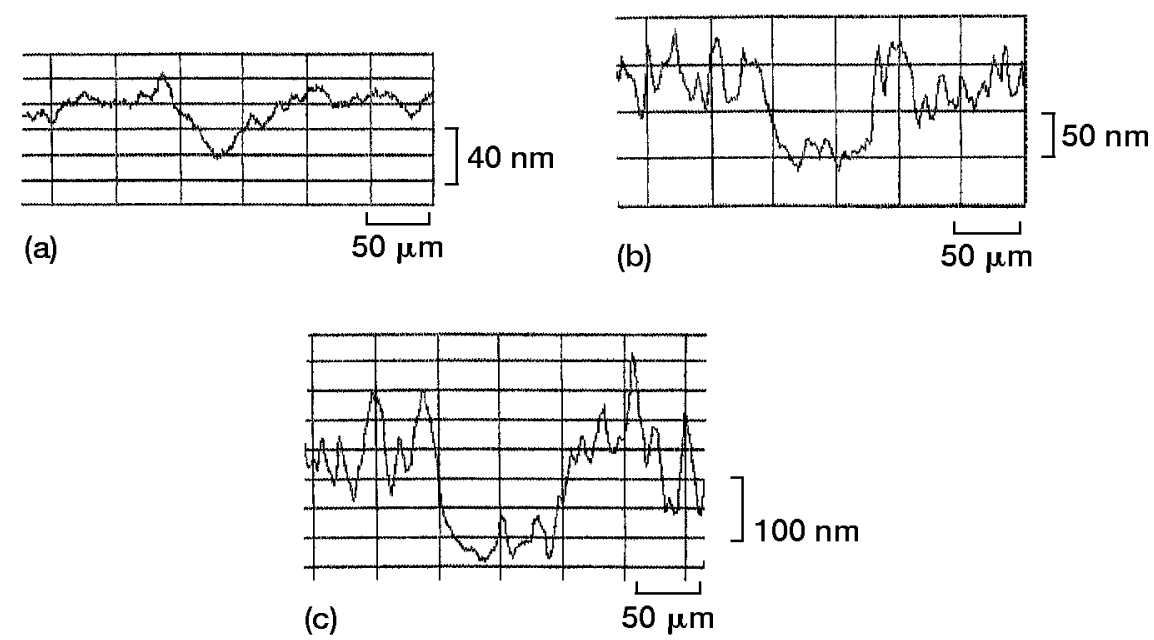

Figure 9.18.-Wear tracks (grooves) on diamond films after 100 passes of bulk diamond pin in ultrahigh vacuum. (a) Fine-grain $(20$ to $100 \mathrm{~nm})$ diamond film on silicon substrate; rms surface roughness, $15 \mathrm{~nm}$. (b) Medium-grain $(1000 \mathrm{~nm})$ diamond film on silicon nitride substrate; rms surface roughness, $52 \mathrm{~nm}$. (c) Coarse-grain (1500 nm) diamond film on $\alpha$-silicon carbide substrate; rms surface roughness, $92 \mathrm{~nm}$.

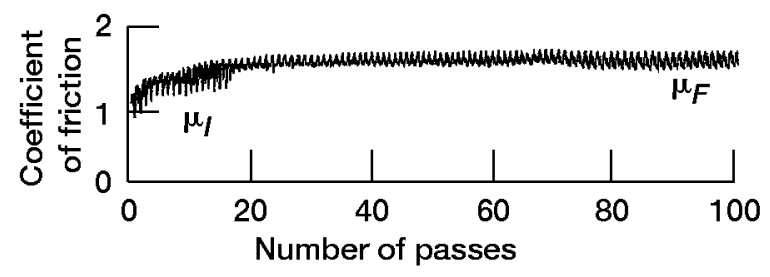

Figure 9.19.-Typical friction trace for bulk diamond pin in contact with diamond film on $\alpha$-silicon carbide substrate in ultrahigh vacuum (initial coefficient of friction, $\mu_{i}$; equilibrium coefficient of friction, $\left.\mu_{F}\right)$.

NASA/TM-1999-107249, Chapter 9 
friction behavior? Which is more important for diamond surfaces in vacuum, abrasion or adhesion?

Removing some of the contaminant surface fil $\mathrm{m}$ from the contact area of diamond films by sliding action resulted in stronger interfacial adhesion between the diamond pin and the diamond films and raised the coefficient of friction, as shown in Fig. 9.19. A contaminant surface film may be removed by repeatedly sliding the diamond pin over the same track in ultrahigh vacuum [9.36].

The friction results shown in Fig. 9.19 are in agreement with other researchers' results for single-crystal diamond rubbing against diamond and for CVD diamond sliding against CVD diamond in vacuum [9.37, 9.38]. At a pressure of $93 \mathrm{nPa}$ Bowden and Hanwell [9.38] observed an initial coefficient of friction of 0.1 for diamond on diamond; within several hundred passes, however, the coefficient of friction rose rapidly to 0.9 and remained constant. Dugger, Peebles, and Pope [9.39] also found that the coefficient of friction increased to 0.47 when CVD diamond slid against itself in vacuum $(<0.6 \mu \mathrm{Pa})$. In both cases the increase in friction was attributed to cleaning the adsorbed contaminants from the surface by rubbing or sliding in vacuum at room temperature.

When sliding continues, the wear dulls the tips of the diamond grains and increases the contact area in the wear track, thereby causing an increase in friction. The increase in equilibrium friction that results from cleaning off the contaminant surface film by sliding and from increasing the contact area is greater than the corresponding decrease in abrasion and friction that results from blunting the tips of surface asperities. This relationship is brought out clearly in Fig. 9.20; here the equilibrium coefficients of friction (1.5 to 1.8 ) are greater than the initial coefficients of friction (1.1 to 1.3 ) regardless of the initial surface roughness of the diamond films. In vacuum, therefore, the friction arises primarily from adhesion between the sliding surfaces of the diamond pin and the diamond films.

The wear rates of the diamond films in ultrahigh vacuum (Fig. 9.21) depended on the initial surface roughness of the diamond films, generally increasing with an increase in initial surface roughness. The wear rates of the diamond films in ultrahigh vacuum were considerably higher than those of the diamond films in humid air or in dry nitrogen (Fig. 9.17). Obviously, under these vacuum conditions adhesion between the sliding surfaces of the diamond pin and the diamond film plays an important role in the higher wear process.

Thus, under vacuum conditions it is adhesion between the sliding surfaces of the diamond pin and diamond films (due to the highly clean state) and the possible presence of dangling bonds that play a significant role in the friction and wear process. The surface roughness of the diamond films does not have much influence on the friction of diamond films in ultrahigh vacuum.

NASA/TM—1999-107249, Chapter 9 


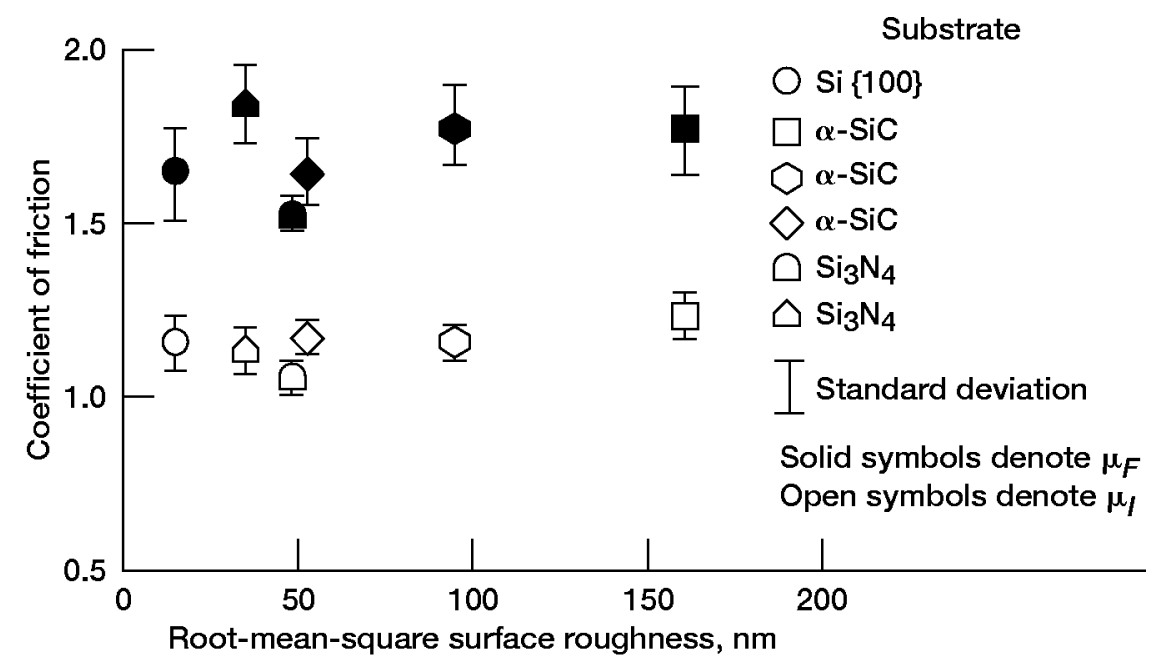

Figure 9.20.-Initial $\left(\mu_{f}\right)$ and equilibrium $\left(\mu_{F}\right)$ coefficients of friction as function of initial surface roughness of diamond films in ultrahigh vacuum.

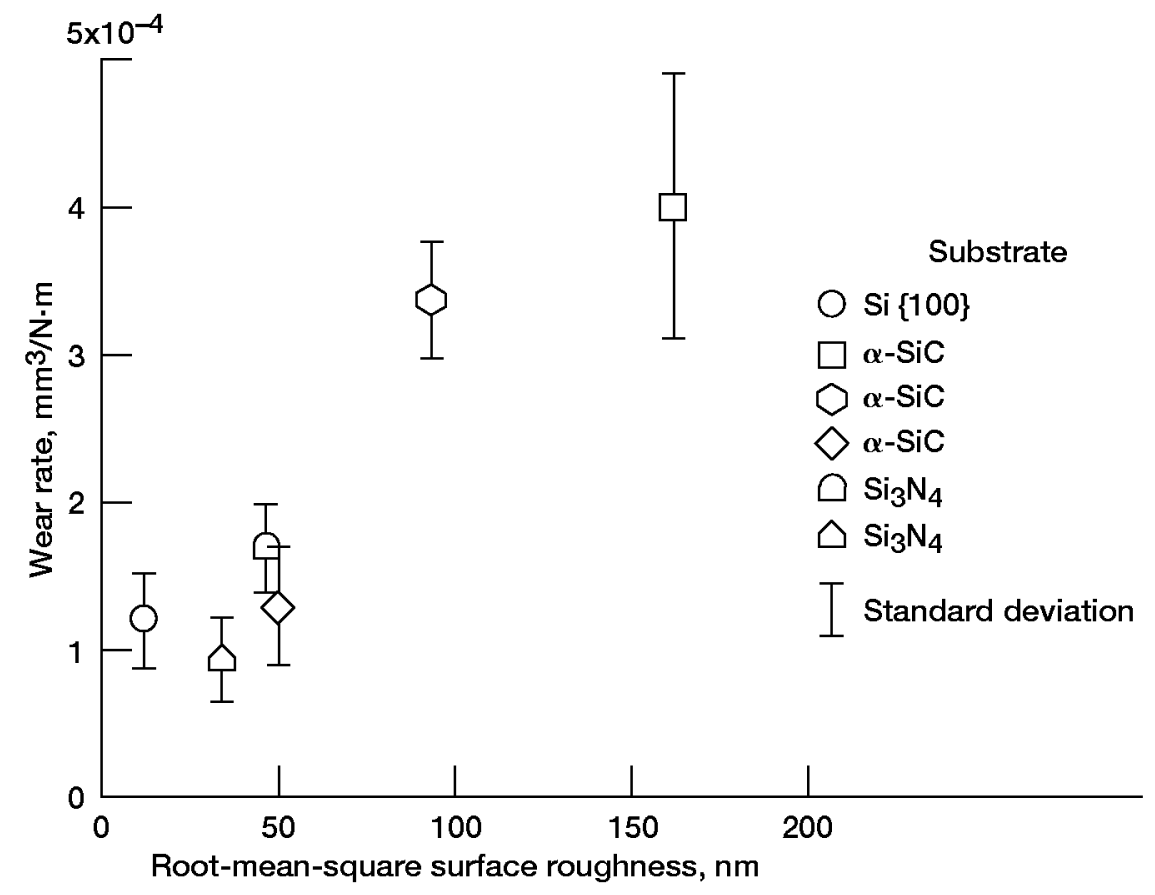

Figure 9.21.-Wear factors of diamond films in ultrahigh vacuum as function of initial surface roughness.

NASA/TM-1999-107249, Chapter 9 


\section{References}

9.1 A.D. Molloy and A.M. Dionne, eds., Wear and Superhard Coatings 1998, Gorham Advanced Materials, Inc., Gorham, ME, 1998.

9.2 K. Miyoshi, ed., special issue on Tribology of Diamond and Diamondlike Films and Coatings (1), Diamond Films and Technology 3,3 (1994).

9.3 K. Miyoshi, ed., special issue on Tribology of Diamond and Diamondlike Films and Coatings, Diamond Films and Technology 4, 1 (1994).

9.4 K. Miyoshi, ed., special issue on Tribology of Diamond and Diamondlike Films and Coatings, Diamond Films and Technology 4, 2 (1994).

9.5 K. Miyoshi, ed., special issue on Tribology of Diamond and Diamondlike Films and Coatings, Diamond Films and Technology 4, 3 (1994).

9.6 H. Windischmann, Stress issues in wafer-scale CVD diamond fabrication, Book of Abstracts, American Vacuum Society, 1998, p. 124; and personal communication.

9.7 D. Haneman, Surfaces of silicon, Rep. Prog. Phys. 50, 8: 1045-1048 (1987).

9.8 J. Wei and J.T. Yates, Jr., Diamond surface chemistry, I. A Review, Critical Reviews in Surface Chemistry 5, 1-3: 1-71 (1995).

9.9 D. Tabor, Adhesion and Friction, The Properties of Diamond, J.E. Field, ed. Academic Press, New York, 1979, pp. 325-350.

9.10 K. Miyoshi and D.H. Buckley, Adhesion and friction of single-crystal diamond in contact with transition metals, Appl. Surf. Sci. 6: 161-172 (1980).

9.11 J.A. Harrison, C.T. White, R.J. Colton, and D.W. Brenner, Molecular-dynamics simulations of atomic-scale friction of diamond surfaces, Phys. Rev. B, 46, 15: $9700-9708$ (1992).

9.12 H.O.Pierson, Handbook of Carbon, Graphite, Diamond and Fullerenes: Properties, Processing, and Applications, Noyes Publications, Park Ridge, NJ, 1993.

9.13 T. Ando, T. Aizawa, K. Yamamoto, Y. Sato, and M. Kamo, The Chemisorption of hydrogen on diamond surfaces studied by high resolution electron energy-loss spectroscopy, Diamond Rel. Mater. 3, 4-6: 975-979 (1994).

9.14 J.E. Butler and F.G. Celri, Vapor phase diagnostics in CVD diamond deposition, International Symposium on Diamond and Diamond-like Films, J.P. Dismukes, ed., The Electrochemical Society, Pennington, NJ, 1989, pp. 317-329.

9.15 T. Yamada, T.J. Chuang, H. Seki, and Y. Mitsuda, Chemisorption of fluorine, hydrogen and hydrocarbon species on the diamond C (111) surface, Mol. Phys. 76, 4: 887-908 (1992).

9.16 T. Ando, K. Yamamoto, M. Ishii, M. Kamo, and Y. Sato, Vapor-phase oxidation of diamond surfaces in oxygen studied by diffuse reflectance Fourier-transform infrared and temperatureprogrammed desorption spectroscopy, J. Chem. Sac., Faraday Trans. 89, 19: 3635-3640 (1993).

9.17 T. Ando, J. Tanaka, M. Ishii, M. Kamo, Y. Sato, N. Ohashi, and S.Shimosaki, Diffuse reflectance Fourier-transform infrared study of the plasma-fluorination of diamond surfaces using a microwave discharge in tetrafluoromethane, J. Chem. Soc., Faraday Trans. 89, 16:3105-3109 (1993).

9.18 T. Ando, K. Yamamoto, S. Suehara, M. Kamo, Y. Sato, S. Shimosaki., and M. Nishitani-Gamo, Interaction of chlorine with hydrogenated diamond surface, J. Chin. Chem. Soc. 42, 2: 285-292 (1995).

9.19 K. Miyoshi, R.L.C. Wu, A. Garscadden, P.N. Barnes, and H.E. Jackson, Friction and wear of plasma-deposited diamond films, J. Appl. Phys. 74, 7: 4446-4454 (1993).

9.20 R.L.C. Wu, A.K. Rai, A. Garscadden, P. Kee, H.D. Desai, and K. Miyoshi, Synthesis and characterization of fine grain diamond films, J. Appl. Phys. 72, 1: 110-116 (1992).

9.21 L.R. Doolittle, Algorithms for the rapid simulation of Rutherford backscattering spectra, Nucl. Instrum. Methods B9: 344-351 (1985).

9.22 J.J. Cheng and T.D. Mautei, Effects of oxygen and pressure on diamond synthesis in a magnetoactive microwave discharge, J. Appl. Phys. 71, 6: 2918-2923 (1992).

NASA/TM-1999-107249, Chapter 9 
9.23 K. Kobashi, K. Nishimura, V. Kawate, and T. Horiuchi, Synthesis of diamonds by use of microwave plasma chemical vapor deposition: morphology and growth of diamond film, Phys. Rev. B 38, 6: 4067-4084 (1988).

9.24 N. Wada and S.A. Solin, Raman efficiency measurements of graphite (and Si and Ge), Physica $B \& C$ 105: 353-356 (1981).

9.25 G. Davies, ed., Properties and Growth of Diamond, INSPEC, Institution of Electrical Engineers, London, UK, 1994.

9.26 K.E. Spear and J.P. Dismukes, eds., Synthetic Diamond: Emerging CVD Science and Technology, John Wiley \& Sons, New York, 1994.

9.27 J.E. Field, ed., The Properties of Diamond, Academic Press, New York, 1979.

9.28 J. Shackelford and W. Alexander, eds., Materials Science and Engineering Handbook, CRC Press, Inc., Boca Raton, FL, 1992.

9.29 W.D. Kingery, Introduction to Ceramics, John Wiley \& Sons, New York, 1960.

9.30 J.B. Wachtman, Jr., ed., Structural Ceramics, Academic Press, Inc., Boston, 1989.

9.31 M. Casey and J. Wilks, The friction of diamond sliding on polished cube faces of diamond, $J$. Phys. D. (Appl. Phys.) 6, 15: 1772-1781 (1973).

9.32 I.P. Hayward, Friction and wear properties of diamond and diamond coatings, Surf. Coat. Technol. 49: 554-559 (1991).

9.33 I.P. Hayward and I.L. Singer, Tribological behaviour of diamond coatings, Second International Conference on New Diamond Science and Technology, Materials Research Society, Pittsburgh, PA, 1991, pp. 785-789.

9.34 I.P. Hayward, I.L. Singer, and L.E. Seitzman, Effect of roughness on the friction of diamond on CVD diamond coatings, Wear 157, 2: 215-227 (1992).

9.35 D. Crompton, W. Hirst, and M.G.W. Howse, The wear of diamond, Proc. R. Soc. London Ser. A 333-1595: 435-454 (1973).

9.36 K. Miyoshi, R.L.C. Wu, and A. Garscadden, Friction and wear of diamond and diamondlike coatings, Surf. Coat. Technol. 54-55, 1-3: 428-434 (1992).

9.37 Z. Feng, Y. Tzeng, and J.E. Field, Friction of diamond on diamond in ultra-high-vacuum and low pressure environments, J. Phys. D. (Appl. Phys.) 25, 10: 1418-1424 (1992).

9.38 F.P. Bowden and A.E. Hanwell, The friction of clean crystal surfaces, Proc. R. Soc. London Ser. A 295: 233-243 (1966).

9.39 M.T. Dugger, D.E. Peebles, and L.E. Pope, Counterface material and ambient atmosphere: role in the tribological performance of diamond films, Surface Science Investigations in Tribology, Y.-W. Chung, A.M. Homola, and G.B. Street, eds., American Chemical Society, Washington, DC, 1992, p. 72.

NASA/TM-1999-107249, Chapter 9 
\begin{tabular}{|l|c|c|} 
1. AGENCY USE ONLY (Leave blank) & $\begin{array}{c}\text { 2. REPORT DATE } \\
\text { February } 1999\end{array}$ & $\begin{array}{c}\text { 3. REPORT TYPE AND DATES COVERED } \\
\text { Technical Memorandum }\end{array}$
\end{tabular}

\section{TITLE AND SUBTITLE}

Chemical-Vapor-Deposited Diamond Film

\section{AUTHOR(S)}

Kazuhisa Miyoshi

\section{PERFORMING ORGANIZATION NAME(S) AND ADDRESS(ES)}

National Aeronautics and Space Administration

Lewis Research Center

Cleveland, Ohio 44135-3191

\section{SPONSORING/MONITORING AGENCY NAME(S) AND ADDRESS(ES)}

National Aeronautics and Space Administration

Washington, DC 20546-0001
WU-523-22-13-00

8. PERFORMING ORGANIZATION REPORT NUMBER

$$
\text { E-9863-9 }
$$

10. SPONSORING/MONITORING AGENCY REPORT NUMBER

NASA TM-1999-107249, Chapter 9

\section{SUPPLEMENTARY NOTES}

Responsible person, Kazuhisa Miyoshi, organization code 5140, (216) 433-6078.

Unclassified - Unlimited

Subject Category: 27

Distribution: Nonstandard

This publication is available from the NASA Center for AeroSpace Information, (301) 621-0390.

\section{ABSTRACT (Maximum 200 words)}

This chapter describes the nature of clean and contaminated diamond surfaces, CVD diamond film deposition technology, analytical techniques and the results of research on CVD diamond films, and the general properties of CVD diamond films. Further, it describes the friction and wear properties of CVD diamond films in the atmosphere, in a controlled nitrogen environment, and in an ultra-high-vacuum environment.

\section{SUBJECT TERMS}

15. NUMBER OF PAGES

35

Solid lubrication; Coatings; Tribology; Fundamentals; Applications

17. SECURITY CLASSIFICATION OF REPORT

Unclassified

18. SECURITY CLASSIFICATION OF THIS PAGE

Unclassified
19. SECURITY CLASSIFICATION OF ABSTRACT

Unclassified 